INVITED REVIEW

\title{
Intraocular light scatter, reflections, fluorescence and absorption: what we see in the slit lamp
}

\author{
Thomas J. T. P. van den Berg \\ Netherlands Institute for Neuroscience, Royal Netherlands Academy of Arts and Sciences, Amsterdam, The Netherlands
}

Citation information: van den Berg TJTP. Intraocular light scatter, reflections, fluorescence and absorption: what we see in the slit lamp. Ophthalmic Physiol Opt 2018; 38: 6-25. https://doi.org/10.1111/opo.12426

\begin{abstract}
Keywords: absorption, crystalline lens, light scatter, reflection, slit lamp, straylight

Correspondence: Thomas J T P van den Berg E-mail address: t.j.vandenberg@nin.knaw.nl
\end{abstract}

Received: 15 August 2017; Accepted: 22 October 2017

\begin{abstract}
Purpose: Much knowledge has been collected over the past 20 years about light scattering in the eye- in particular in the eye lens- and its visual effect, called straylight. It is the purpose of this review to discuss how these insights can be applied to understanding the slit lamp image.

Results: The slit lamp image mainly results from back scattering, whereas the effects on vision result mainly from forward scatter. Forward scatter originates from particles of about wavelength size distributed throughout the lens. Most of the slit lamp image originates from small particle scatter (Rayleigh scatter). For a population of middle aged lenses it will be shown that both these scatter components remove around $10 \%$ of the light from the direct beam. For slit lamp observation close to the reflection angles, zones of discontinuity (Wasserspalten) at anterior and posterior parts of the lens show up as rough surface reflections. All these light scatter effects increase with age, but the correlations with age, and also between the different components, are weak. For retro-illumination imaging it will be argued that the density or opacity seen in areas of cortical or posterior subcapsular cataract show up because of light scattering, not because of light loss.

Notes: (1) Light scatter must not be confused with aberrations. Light penetrating the eye is divided into two parts: a relatively small part is scattered, and removed from the direct beam. Most of the light is not scattered, but continues as the direct beam. This non-scattered part is the basis for functional imaging, but its quality is under the control of aberrations. Aberrations deflect light mainly over small angles $\left(<1^{\circ}\right)$, whereas light scatter is important because of the straylight effects over large angles $\left(>1^{\circ}\right)$, causing problems like glare and hazy vision. (2) The slit lamp image in older lenses and nuclear cataract is strongly influenced by absorption. However, this effect is greatly exaggerated by the light path lengths concerned. This obviates proper judgement of the functional importance of absorption, and hinders the appreciation of the Rayleigh nature of what is seen in the slit lamp image.
\end{abstract}

\section{Basic physics of light entering the eye}

Light - matter interaction

When light enters the eye, its transportation through the ocular media is by no means trivial. From basic physics on the interaction between light and matter we know that light is an electromagnetic radiation, and that it excites matter, which then starts functioning as an emitter of light itself. The most well-known effect is the blue light of the sky
(Figure 1). In the case of natural light (light with all polarisation directions), this emission takes place in all directions. Figure 2 gives the precise angular distribution of this emission for a small piece of matter (red). So, starting with the cornea and all subsequent eye media, the eye media basically emit light. However, in the case of very homogeneous matter, like glass or water, the emitted light interferes destructively in most directions. In precise backward directions only a small percentage is what we call reflected, 


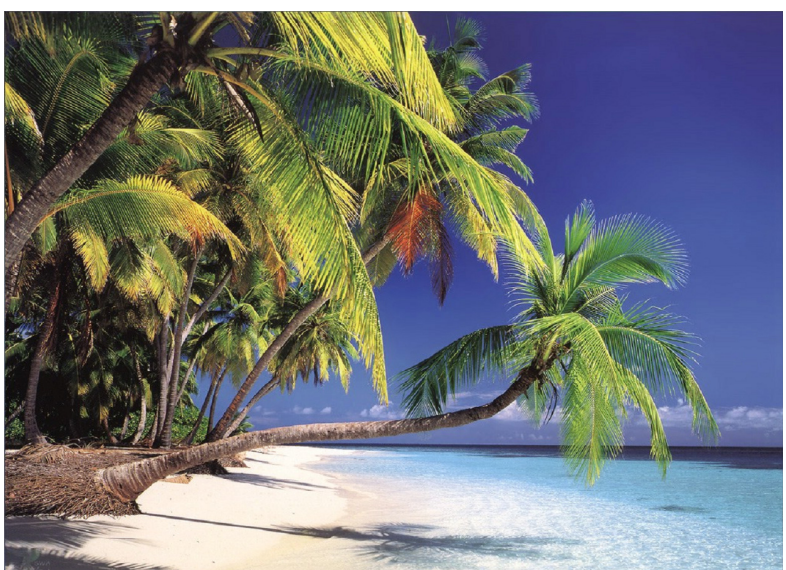

Figure 1. Most of what we see, we see because of light scattering. Opaque objects (the beach, the trees) are seen because multiple scattering in superficial layers result in back scatter. The transparent air in the sky is seen because of scattering in all directions with strong short wavelength (blue) dominance.

giving rise to the Purkinje images in the case of the eye. Most of the light is transmitted in forward direction, but with somewhat different velocity due to this reemission process. This difference in velocity is translated into a difference in refractive index, and that is the measure used to describe how the light path continues into the eye.

\section{Rayleigh - basic scattering}

We are all well acquainted with this basic process of excitation and reemission by what we see around us (Figure 1). The blue of the sky is the classic example. The rays of the sun transgress the air overhead us and excite the air molecules, which then function as light emitters, sending light in all directions. That is why we see the blue of the sky all over the sky. From Figure 2 we can gather that the intensity has a weak minimum at right angles to the direction of the sun's rays. This minimum is caused by the fact that re-emission only takes place at right angles to the direction of polarisation. The sun emits light of all polarisation directions, but the axis of polarisation is always perpendicular to the direction of the light ray. So, at right angles to the light ray only half of the polarisations contribute. Indeed, if we use Polaroid sunglasses to look at the sky, we can clearly see a dark band in the blue of the sky. This basic process was quantitatively formulated by John William Strutt (the later Lord Rayleigh) in a series of papers up to the year 1900 as follows:

$$
I=I_{0} \frac{1+\cos ^{2} \theta}{2}\left(\frac{n^{2}-1}{n^{2}+2}\right)^{2}\left(\frac{2 \pi a}{\lambda}\right)^{4} \frac{a^{2}}{r^{2}} R(\theta)
$$

with $I_{0}$ and $I$ incident and scattered intensity respectively, $\theta$ scatter angle, $\lambda$ the wavelength of the light, $n$ and $a$ refractive index and radius of the particle respectively, and $R$ added for future convenience. $R(\theta) \equiv 1$ for particles small compared to wavelength, the classic Rayleigh condition. The term $\left(1+\cos ^{2} \theta\right) / 2$ is called the natural light correction because natural light has all polarisation directions. When ${ }^{1}$ is integrated over full angular space one gets the total amount of light scattered expressed as scattering cross section $\sigma_{s}$ :

$$
\sigma_{s}=\frac{8}{3}\left(\frac{n^{2}-1}{n^{2}+2}\right)^{2}\left(\frac{2 \pi a}{\lambda}\right)^{4} \pi a^{2}=Q \pi a^{2}
$$

$Q$ is the fraction of the light falling on the geometrical cross section $\pi a^{2}$ of the particle that is scattered. These equations show the well-known strong wavelength

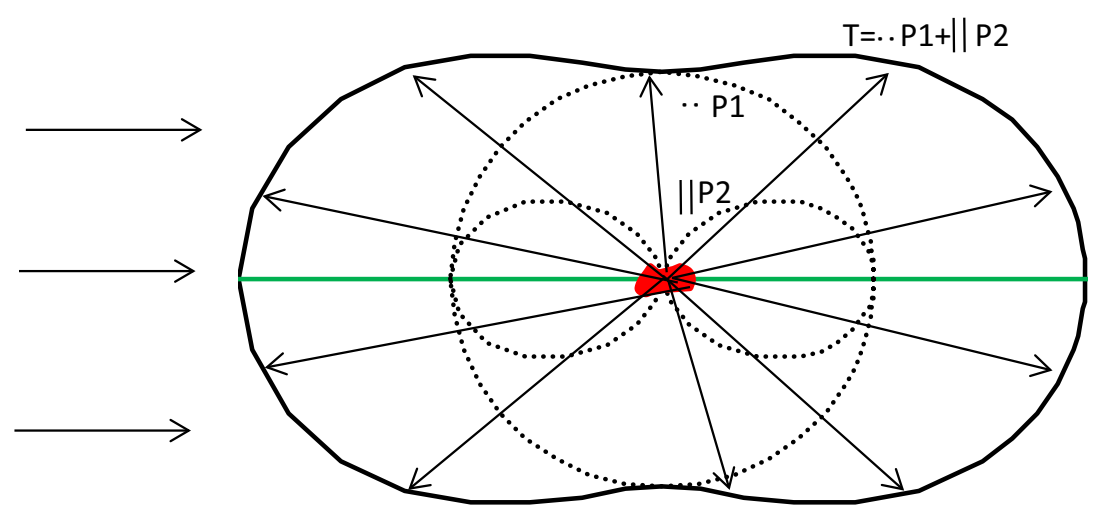

Figure 2. Rayleigh scattering. Natural light (coming from the left) contains polarisations in all directions perpendicular to the direction of propagation. No scattering of light takes place in the direction of polarisation. So, light polarised perpendicular to the plane of the drawing (P1) is scattered equally strongly in all directions in the plane of the drawing (dotted circle). Light polarised in the plane of the drawing (P2) does not scatter in vertical direction (two-lobed dotted line). Both components sum up to the continuous line ( $\mathrm{T}=\mathrm{P} 1+\mathrm{P} 2)$ giving total scatter for natural light. 
dependence of small particle scattering, causing the intense blue of the sky. They also show that the scattering efficiency $Q$ is very strongly dependent on particle size, relative to wavelength, as expressed by the term $2 \pi a / \lambda$. The quantity $x=2 \pi a / \lambda$ plays a pivotal role in scattering theory. For particles as small as air molecules this term is extremely small. Otherwise the air would be opaque.

As result of these relationships, with the sun at its zenith (vertically above our head) the atmosphere scatters about $30 \%$ of the sun's light at $400 \mathrm{~nm}$ and about $7 \%$ at $600 \mathrm{~nm}$ before it reaches our eye. At sunset the atmospheric layer between our eyes and the sun is about 40 times longer. This means that direct $400 \mathrm{~nm}$ light is weakened by a factor $0.70^{40}$, so virtually none of the $400 \mathrm{~nm}$ light is left. For $600 \mathrm{~nm}$ weakening would be $0.93^{40}=0.055$. So, scatter causes a strong spectral filtering, with the deep red colour of the sun at sunset as result. The blue of the sky is but one example of excitation and re-emission that we see in the world around us. Another example is the light scattering by clouds. The cloud particles are much larger than wavelength, causing scattering to be virtually independent from wavelength, which is why the clouds are white.

\section{Eye media as scattering system}

For a discussion of the eye media, relatively simple systems will be used that can be considered intermediate cases, when matter neither consists of independent small particles (molecules), nor a homogeneous material like pure water, but a combination of both. In the case of the eye media, in particular the cornea and the lens, we do have rather homogenous materials, though not perfectly homogeneous. The light is basically scattered as explained above, but due to the near-homogeneity the scattered light is quenched to a large extent because of destructive interference. In fact only the irregularities in those media structures need be considered, such as the collagen fibrils in the cornea and the lens proteins, relative to the near-water matrix they are embedded in. It must be noted that there are few mitochondria and other large intracellular organelles in the lens, and those present are hidden behind the iris so as not to scatter light. The older, more central lens fibres lose their intracellular organelles. As an approximation, it is normally assumed that we only need to consider first, a change in wavelength when light penetrates into the eye and second, scattering by irregularities with respect to the near-water matrix.

\section{Slit lamp image and Rayleigh scatter}

\section{Transparency of the eye media}

It was realised quite some time ago that the optical quality of the eye, and particularly the cornea and lens, was no trivial matter. Maurice's classic 1957 paper 'The structure and transparency of the cornea' ${ }^{\prime 1}$ suggested that the collagen fibrils would scatter $94 \%$ of the light if they were acting independently, and the cornea would be nearly opaque. He argued that regular ordering of the fibrils, according a kind of crystalline structure, caused destructive interference, giving the cornea its transparency. In Trokel's 1962 paper 'The physical basis for transparency of the crystalline lens' ${ }^{2}$ he pointed out that the same holds for the protein molecules of the lens, and argued that the high concentration of protein causes spatial ordering approaching a paracrystalline state.

Those studies used morphological and biochemical knowledge about the eye media. Important further studies are from the groups of Benedek and Thurston, ${ }^{3,4}$ Bettelheim, ${ }^{5,6}$ Tardieu and Delaye, ${ }^{7}$ McCally and Farrell, ${ }^{8}$ and Meek. ${ }^{9,10}$ The relationship with functional in vivo straylight measurements was not made. Our own work has been to study the functional aspects of light scattering. We wanted to understand forward light scattering (light scattered from the cornea and lens towards the retina), as it results in the visual effect of straylight. We also wanted to know the relationship of forward light scattering/straylight to backward light scattering, which is the light scattering seen in the slit lamp. To this purpose we set out to measure light scattering from human eye lenses, combining in one measurement forward and backward directions. Figure 3 shows the set-up. ${ }^{11}$

\section{Lenticular scatter data and Rayleigh scattering}

The middle part of Figure 3 shows schematically the cuvette with the human eye lens, and the angles of measurement. The angles were chosen in symmetrical pairs with respect to $90^{\circ}$ : $140^{\circ}$ to $40^{\circ}, 152^{\circ}$ to $28^{\circ}, 165^{\circ}$ to $15^{\circ}$, and additionally $10^{\circ}$. This choice was made to enable sensitive testing for potential Rayleigh type of scattering. Figure 2 shows that these pairs should give identical values in the case of Rayleigh scattering. This comparison is of additional interest because it would link directly the functional (forward; towards the retina) scatter, and the slit lamp observation (backward scatter). The measurements were moreover done at four wavelengths: 400, 500, 602, and $700 \mathrm{~nm}$. A problem arises because part of the light is absorbed, especially at the shorter wavelength. To tackle this problem, first for each wavelength total light transmission was measured, and corrections were made according to the length of the light path for each condition. Because corrections were often huge for $400 \mathrm{~nm}$, causing inaccuracy, the $400 \mathrm{~nm}$ data were excluded from use for much of the analysis. Results are presented in terms of the point spread function (PSF), properly normalised (the integral of the PSF over solid angle is unity), to enable direct comparison with the 


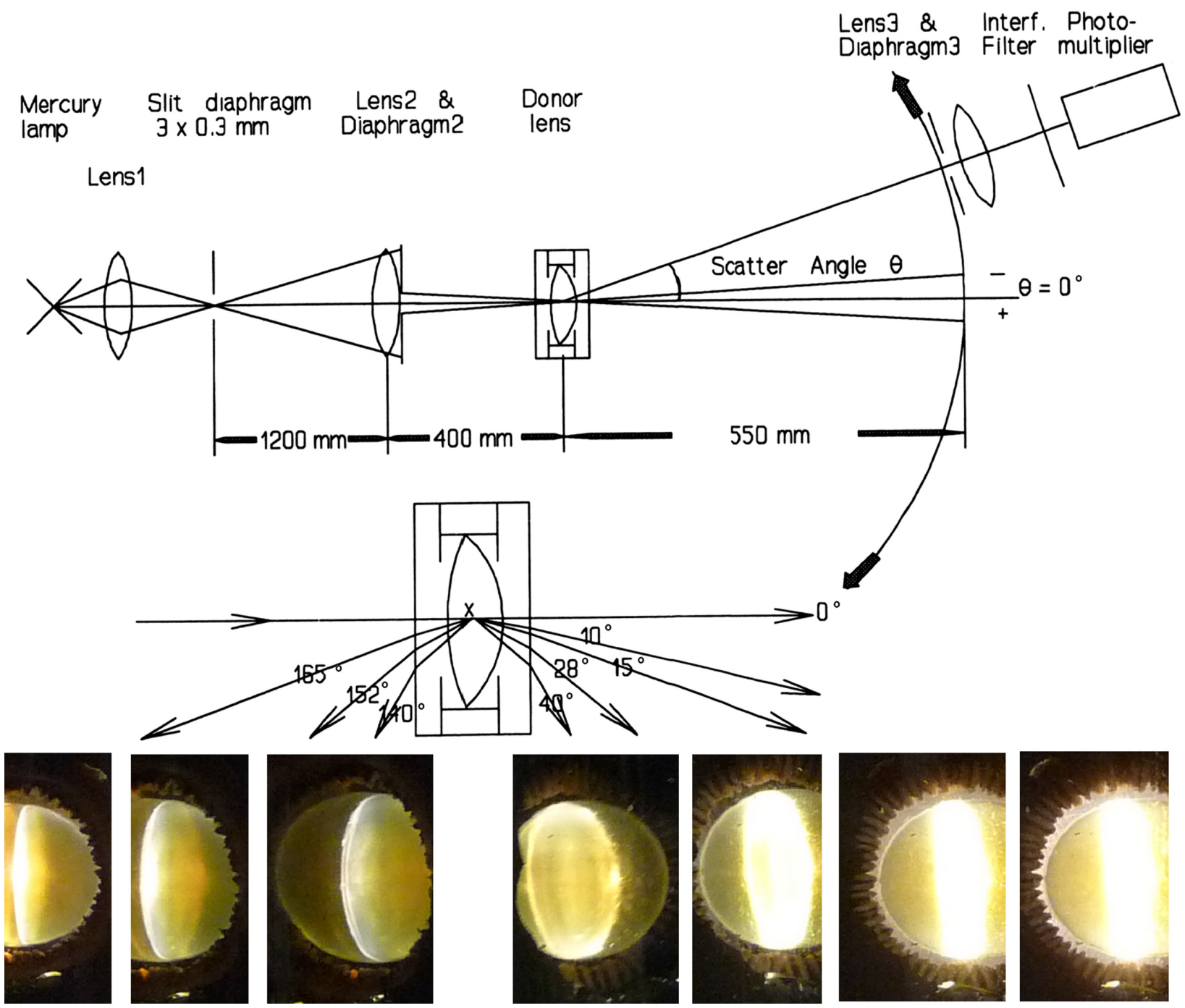

Figure 3. Set-up for measuring light scattering from fresh human donor lenses. An extra interference filter was added between the slit diaphragm and Lens 2 in case of fluorescence measurements. The middle part of the figure shows an enlarged view of the cuvette with the donor lens, and the angles of measurement in case of depth resolved measurements. A recording of the narrow pencil beam at $\theta=0^{\circ}$ was made to estimate total transmitted light as means of normalisation. The recordings at other values of $\theta$ were divided by this normalization value and by the receptance angle in steradian, to arrive at the $\theta$-dependent values of the point spread function (PSF) presented in the figures. For precise methods and results please see van den Berg and Spekreijse. ${ }^{21}$ The figure is adapted from an earlier paper. ${ }^{11}$ At the bottom, slit lamp photos are added for a $10 \times 0.2 \mathrm{~mm}$ slit as illustration, taken at the corresponding angles, for a fixated donor eye lens in a round vial, not part of the original study.

functional in vivo PSF. The PSF is defined as the amount of light per unit of solid angle (the steradian). The PSF of the normal eye is strongly peaked forwards towards the retina. It has a value of about $10^{7}$ in the direction $\theta=0^{\circ}$.

Results are shown in Figure 4 for the longer three wavelengths. It gives the comparison between $140^{\circ}$ and $40^{\circ}$. It can be seen that the identity $(y=x)$, expected according the Rayleigh pattern shown in Figure 2, is followed by most of the lenses. The same data was used to test the wavelength dependence to be expected for Rayleigh type of scattering.
This is shown in Figure 5 for the comparison between 500 and $700 \mathrm{~nm}$ at the $140^{\circ}$ scatter angle. Figure 5 shows that the data follow the difference in scatter according the Rayleigh prediction: $1 / \lambda^{4}=>0.58 \log$ unit difference $(\log (700 /$ $\left.500)^{4}=\log 3.84=0.58\right)$.

The slit lamp image and Rayleigh scattering

Figure 6 shows for reference the LOCS III system for categorising and grading cataracts. ${ }^{12}$ The upper row gives slit 


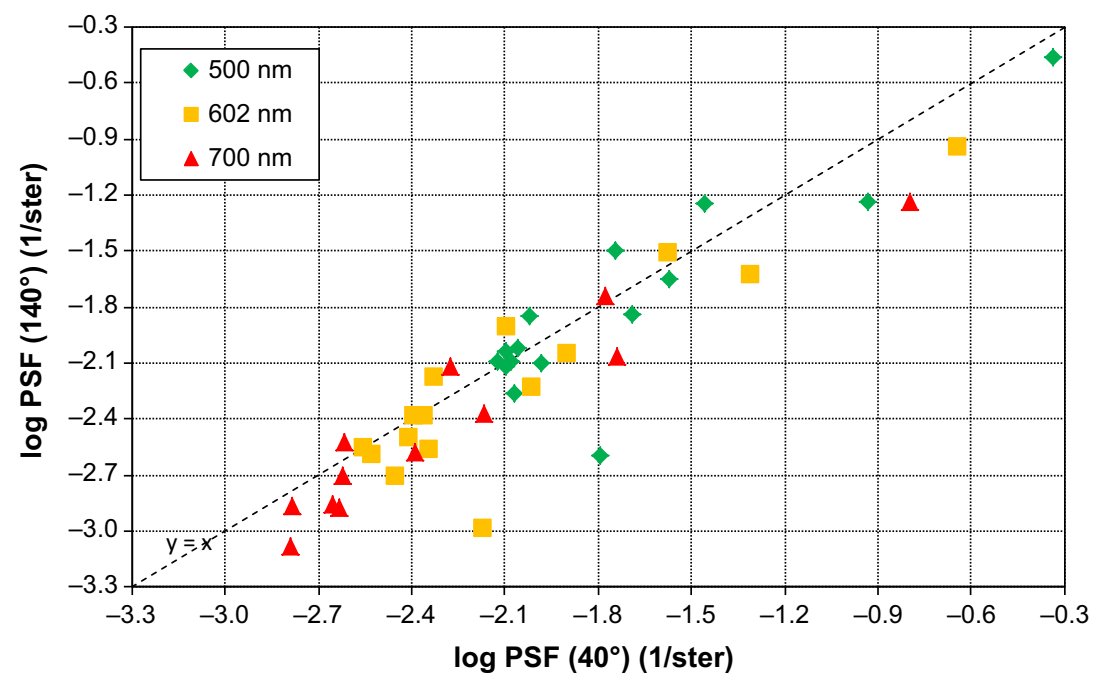

Figure 4. Test for symmetry of light scattering with respect to $90^{\circ}$, as appropriate for Rayleigh scatter. For each lens three wavelengths are shown. Most lenses oblige. Three lenses (points below the $y=x$ line) show some deviation from Rayleigh behaviour. In those three cases the larger particle component (strong forward scatter) was relatively strong compared to the Rayleigh component, and intrude at $40^{\circ}$. The figure suggests that at $140^{\circ}$ (backward; slit lamp angle) rather pure Rayleigh behaviour may dominate.

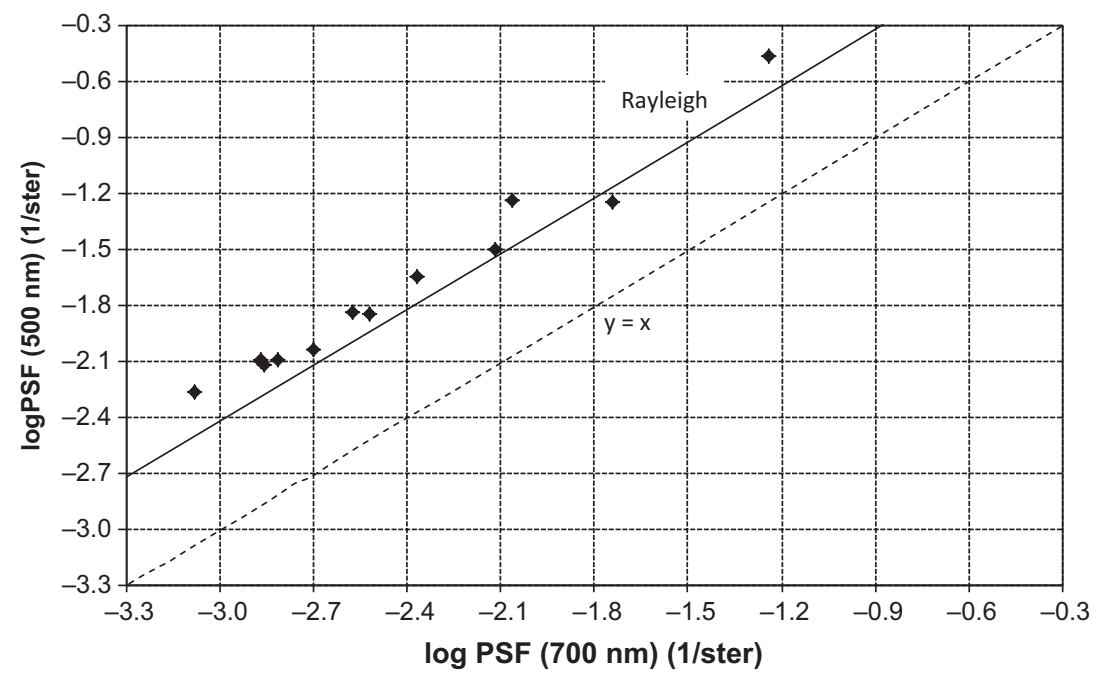

Figure 5. Test for wavelength dependence as appropriate for Rayleigh scatter, at $140^{\circ}$ scatter angle (backward; slit lamp angle). A close correspondence is seen.

lamp images, showing optical sections of both cornea and lens. In those images the lens shows strong colour effects. For lower grades a bluish colour is seen at the anterior side, changing into a strong yellow colour for higher grades at the posterior side. The yellow colour for grades N4-N6 is so clear that it may be hard to believe that the light we are looking at derives from Rayleigh scattering. Yet also in these images this can somewhat be appreciated. In all cases the yellow colouring is not present at the anterior part of the lens, and only develops with increasing depth. Data from literature shows that the colouring effect of the yellow pigment can easily overwhelm the basic colour of Rayleigh scatter. For example: at $400 \mathrm{~nm}$ the absorptive effect over full lens depth is usually $1 \log$ unit or more, starting at young age. ${ }^{13}$ What we see in the slit lamp image on the posterior side is light that has travelled twice (forwards and backwards) through the lens, partly at oblique angles. So, the attenuation more than doubles, and is more than $2 \log$ units. If we compare Rayleigh scatter at $400 \mathrm{~nm}$ to that from the middle of the 


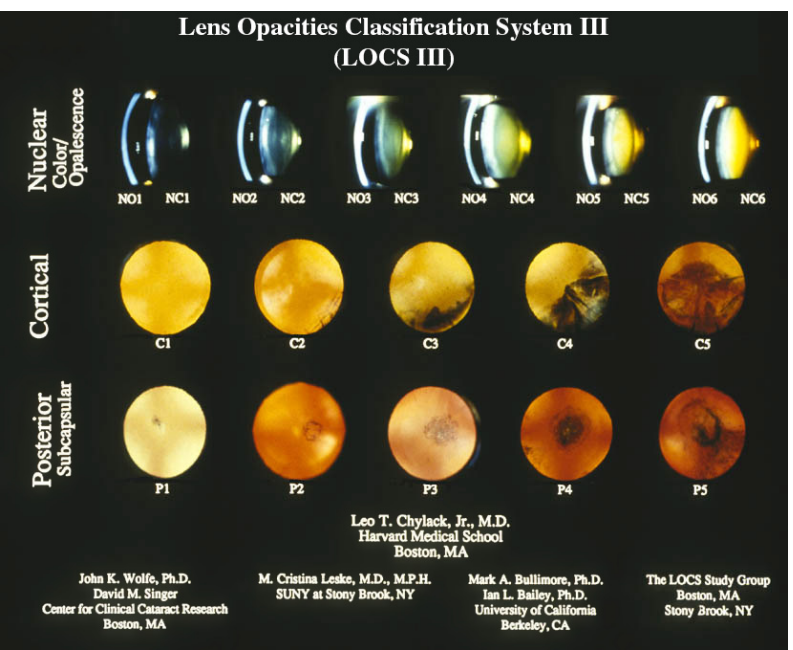

Figure 6. Photograph of the LOCS III score chart. ${ }^{12}$

visual spectrum $(550 \mathrm{~nm})$, the difference is $\log (550 /$ $400)^{4}=\log 3.57=0.55 \log$ units. So, the absorptive effects on colour easily dwarf the colour of the basic effect of light scattering we see at the slit lamp.

However, what about really young lenses, with little absorptive effects? One would expect these to be more clearly bluish over a large part of the lens. However, this is not easily seen because young lenses appear dark on slit lamp observation, as the left-most example in the first row of Figure 6. The light intensity and recording sensitivity of a normal (photo) slit lamp is not designed to visualize very clear young lenses. In order to visualize the weak backscattered light of young lenses one needs to overexpose. This is shown in Figure 7. To the left is the slit lamp image for a 16-year-old eye with normal exposure, and to the right with overexposure. The typical blue colour we know from the sky can be seen.

\section{Eye media transparency achievement}

What about the absolute amounts of light scattered we found, in relation to the above mentioned ideas on transparency achievement of the eye media? Figures 4 and 5 show that the PSF has values around 0.01 for $140^{\circ}$, which means that at this angle $1 \%$ of the light is scattered per steradian. How does this experimental result relate to the above mentioned theory, predicting light scattering from (protein) particles?

For this we use the data of Tardieu and Delaye who studied the quenching effect of destructive interference for calf lenses. ${ }^{14}$ They estimated at a wavelength of $500 \mathrm{~nm} 12 \%$ scatter in total for a protein concentration of $0.12 \mathrm{~g} \mathrm{~mL}^{-1}$, reducing to $3 \%$ scatter in total for a protein concentration of $0.4 \mathrm{~g} \mathrm{~mL}^{-1}$. From their Figure 6 one can derive that without quenching these values would have been $30 \%$ and $69 \%$ respectively. ${ }^{14}$ If we assume for the human eye lens $4 \mathrm{~mm}$ thickness instead of the $10 \mathrm{~mm}$ of calf lenses, and the same $0.4 \mathrm{~g} \mathrm{~mL}^{-1}$ concentration, we get an expected $1-0.31^{4 / 10}=37 \%$ of light scattered by human eye lenses. So, Figures 4 and 5 show us the efficiency of spatial order in human eye lenses to suppress light scattering. In the clinic those same intensities are viewed with slit lamp observation, and the conclusion must be that slit lamp observation shows us the scatter suppression effect of destructive interference. However, this only relates to the Rayleigh component of light scattering, and as we will see this component may not be very important for functional vision.

Maurice measured backscatter for healthy human corneas over backward half space, and found $0.1 \%$ for red light and $0.3 \%$ for blue light. ${ }^{1}$ Considering that the cornea is much thinner than the lens, these values correspond more or less to those of the lens as reported presently, including the Rayleigh type of wavelength dependence. This is in agreement with slit lamp observation, showing both cornea and anterior side of the lens to be blueish at about the same intensity.

Other studies also looked at backscatter quantitatively, but without spectral definition, which makes them harder to interpret. Allen and Vos, ${ }^{15}$ using calibrated black and white photographic film, found around $0.5 \%$ backscatter for the cornea. For total scatter from lens and cornea they report $1 \%$ at 20 years of age, rising to around $4 \%$ at 80 years of age with quite some variation. Weale reported about the same values for the lens. ${ }^{16}$ With crossed polarisers he moreover studied the ratio between randomly backscattered and reflected light. For clinical work, the importance of quantitative standardisation has been stressed, but the results cannot be compared with the present results, as they are not defined in percentage back scatter. ${ }^{17}$

\section{Forward light scatter}

Strength and wavelength dependence

Figure 8 shows the comparison between light scatter at $10^{\circ}$ (horizontal axis) with that at $140^{\circ}$ (vertical axis). These data are from the same study as Figures 4 and 5. It is immediately clear that forward light scatter (at $10^{\circ}$ ) is much stronger than backward light scatter (at $140^{\circ}$ ), and that the two are not very precisely related. Figure 9 shows that the wavelength dependence of this forward scatter $\left(\right.$ at $\left.10^{\circ}\right)$ does not follow that shown by Rayleigh scattering, nor is it spectrally neutral as for large particles, but somewhat in between. From physical light scattering theory it is clear that particles of intermediate size must be responsible. We 


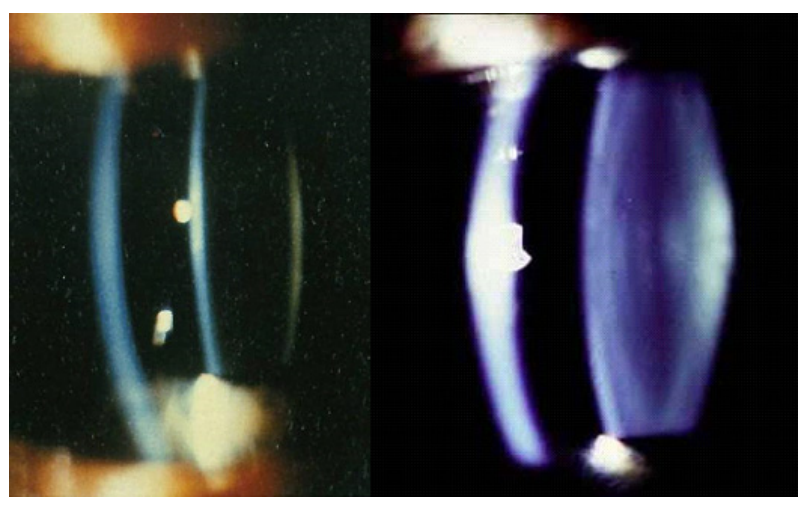

Figure 7. For young eyes, normally the slit lamp image shows a dark interior of the lens (left). When overexposure is used (right), one can appreciate the sky blue colour typical of Rayleigh scattering.

fitted the complete set of data (three wavelengths and seven angles) with light scattering theory and found a perfect match for a combination of (1) particles much smaller than wavelength, and (2) particles of about $0.7 \mu \mathrm{m}$ radius. For the particles of intermediate size we used the so-called Rayleigh-Gans approximation ${ }^{18}$ assuming the particles to be protein aggregates as indicated by the biochemical studies mentioned above. However, Costello et al. found so called multilamellar bodies, and showed that these are good alternative candidates. ${ }^{19,20}$ Figure 10 shows an example of the fit result for one lens of a 50-year-old donor, adapted from an earlier publication. ${ }^{21}$

\section{Significance of light scattering for visual function}

Straylight and glare concepts

Starting in the early 1900s studies have accumulated showing that the visual problem of glare derives from the optical phenomenon of light scattering in the eye. ${ }^{22}$ Light scattering causes a veil of light superposed over the image seen. This veil can be quantified with its visual intensity according photometric principles as equivalent luminance in

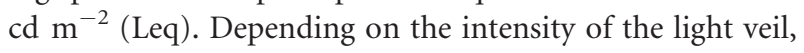
vision is weakened or lost. The optical quality of the eye is comprehensively defined by means of the PSF. The PSF is often defined only for a very small central portion, say up to $20 \mathrm{~min}$ of arc, and with the peak set equal to one. For a discussion of visual significance it must be defined more fully, and functionally, that is as the light spreading affecting vision. The peripheral part of the PSF, for angles larger than $1^{\circ}$, derives from light scattering. It can be defined as Leq/Ebl, where Ebl is the illuminance on the eye from the point source. Using this definition, the PSF is properly normalised. The peripheral part is called straylight, and psychophysical techniques have been designed for its clinical measurement. ${ }^{23-30}$ Ginis et al. also designed an optical approach, ${ }^{31}$ avoiding problems of the double pass technique. $^{32,33}$ Since the PSF is approximately shape invariant above $1^{\circ}$, one parameter suffices to describe it, called the straylight parameter. It is defined as

$$
s=\theta^{2} \mathrm{PSF}
$$

where $\theta$ is the visual angle. In normal eyes on average the following approximate relation with age applies: ${ }^{30}$

$$
\log (s)=0.9+\log \left(1+(\text { age } / 65)^{4}\right)
$$

A clinical instrument exists to measure this quantity, the C-Quant (www.oculus.de), based on a psychophysical technique including quality control. ${ }^{30,34}$ Because the phenomenon of glare precisely corresponds with straylight, the International Commission on Illumination (CIE) decided that glare must be quantified with straylight. ${ }^{22}$ The CIE also defined age norms for glare/straylight by means of the PSF. $^{30,35}$

\section{Straylight as part of the point spread function}

Figure 11 shows the PSF in comparison to light scattering results and is adapted from a recent publication in the present journal. ${ }^{36}$ The black line gives the normal CIE PSF function. It is compared to the light scattering results just described for two of the lenses. The light green lines are for the (normally aged) lens of the present Figure 10. The dark green lines are for the densest lens of the respective study. ${ }^{21}$ The virtually horizontal lines describe the Rayleigh component, and the curved lines describe the intermediate particle size component, both for the middle of the visual spectrum. The red line gives the effect of (small) aberrations normal in healthy eyes, affecting only the central portion of the PSF. The aberrations were modelled according to the model of Thibos, Applegate et al. ${ }^{37,38}$

If we consider the periphery of the PSF, it is clear that a near perfect correspondence exists for the normal eye between the light scatter results in vitro and the in vivo straylight results. It is also clear that the Rayleigh component is of little significance for this aspect of visual function. The dark green line shows that increased light scattering in a cataractous lens can give a strong elevation to the peripheral part of the PSF, in accordance with psychophysical straylight assessment in cataract. $^{39,40}$ In studies of normal ageing and with different morphological types of cataract, it was found that the angular dependence of straylight does not change much. ${ }^{41}$ This was implemented in the CIE PSF model with an age parameter. Using this result to model scattering, cataract can be modelled as increased ageing. The 
grey line in Figure 11 was obtained with the age parameter set to 110 years although it should be noted that this condition is rather extreme as normally such cataract would have been treated with surgery. ${ }^{40}$

\section{Scatter diagrams for the lens}

Figure 12 shows the complete light scattering diagram for the lens of Figure 10 as it is normally given in light scattering studies in physics. Figure $12 a$ gives the full scatter diagram. This presentation makes it very clear how strongly light scattering is in the forward direction. Yet, at the precise zero direction, it is feeble compared to the main PSF peak, as can be seen in Figure 11. The PSF peak is so narrow, and so huge in comparison, that it cannot be shown in a presentation like that of Figure 12. To show the relation with the backward/Rayleigh scattering we see in the slit lamp, Figure 12b,c give magnifications of Figure $12 a$ by $10 \times$ and $100 \times$ respectively. The backward/slit lamp intensity is by comparison very low, and one might think that the total amount scattered by the small particles is much less than the total amount scattered by the intermediate particles. However, this is not the case.

\section{Light transmission and extinction}

At this point we must clarify some notions related to light transmission into the eye. In discussions of cataract sometimes words like density or opacity are used. Optical density or OD is defined as $\log$ (Iincident/Itransmitted), or $10 \times$ that amount, in which case it is called $\mathrm{dB}$ (decibel). For example, for a transmission of $5 \%$ optical density is 1.3 or
$13 \mathrm{~dB}$. It is often assumed that the cataract density or opacity reduces the light entering the eye. We will ignore light loss due to yellow pigments for the present, and consider whether scattered light significantly reduces light entering the eye.

In studies on eye media transmission, the importance of light scattering was realized already by Boettner and Wolter in 1962, and a distinction between direct transmittance and total transmittance was made. ${ }^{42}$ In practice, direct transmittance includes light scattered over acceptance angle, which had a diameter of about $2^{\circ} .{ }^{42}$ To calculate the more precisely defined fraction removed from the direct beam by light scattering (extinction), we need to integrate the diagrams of Figure 12 over the full $4 \pi$ of solid angle. For Rayleigh scattering this is $8 \pi / 3$ times the value in the $0^{\circ}$ or $180^{\circ}$ directions. For the non-Rayleigh component this must be done numerically. However, a correction had to be made. Light scatter results are given relative to the amount of incident light. This amount is usually estimated by measuring the total amount of light in the forward transmitted peak. An acceptance angle of $2^{\circ}$ would be considered to catch in most cases virtually all of the light in a normal PSF, but this is not precise as indicated above.

The results are given in Figure 13. Results for three lenses are indicated with numbers 1-3. Figure 10 comes from Lens 1 . We see that extinction in this group of lenses (4382 years of age) is around 10\% for both the Rayleigh component and the forward component. However the retinal light level would reduce by much less than $2 \times 10 \%$, since most of the light is scattered towards the retina. For the Rayleigh component half of the scattering is towards the retina, and for the non-Rayleigh component almost all. So,

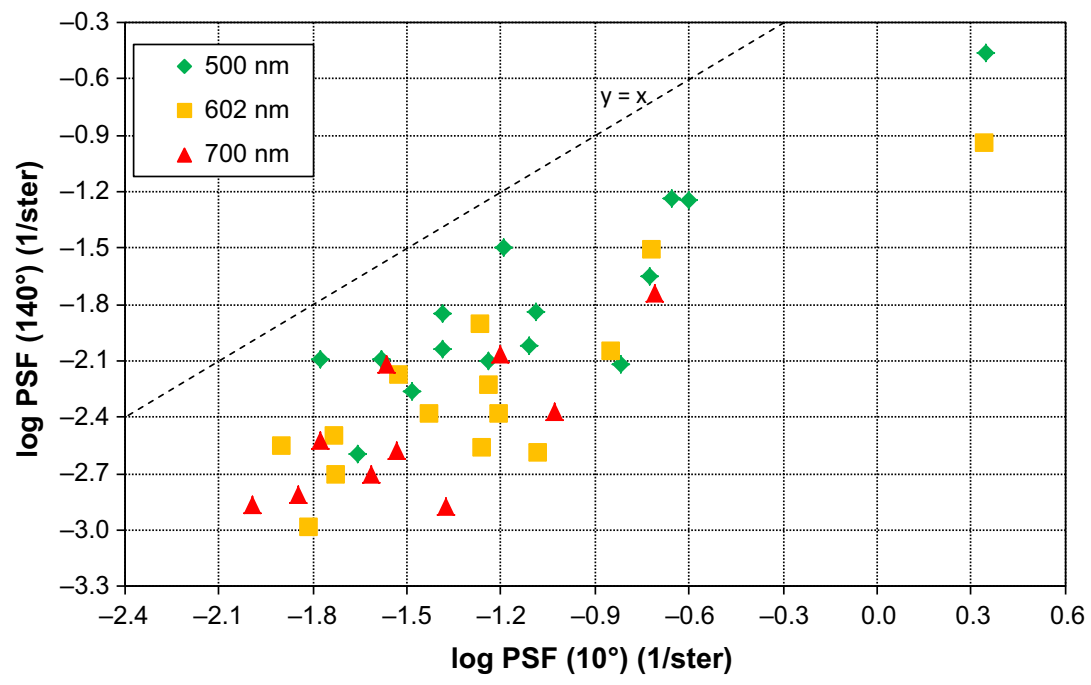

Figure 8. Forward light scatter (horizontal) is much stronger than the Rayleigh component, pointing to the presence of another class of light scattering particles, not small compared to wavelength. 


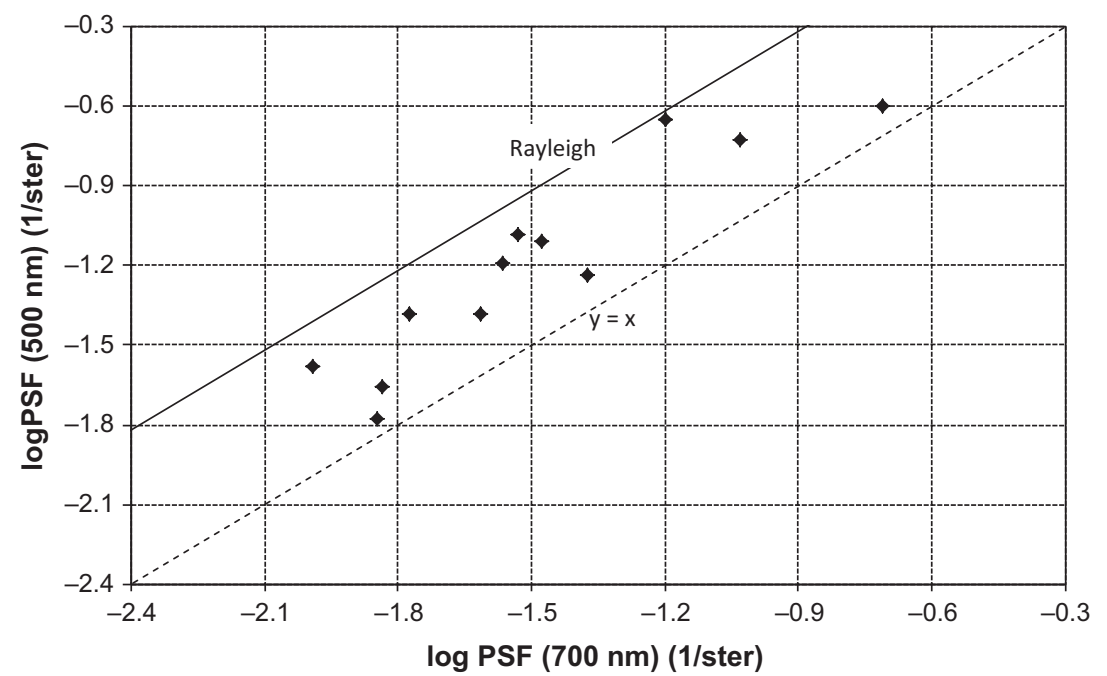

Figure 9. The forward light scatter at $10^{\circ}$ shows wavelength dependence in between Rayleigh, and neutral $(y=x)$. This points at particles responsible that are neither small, nor large compared to wavelength.

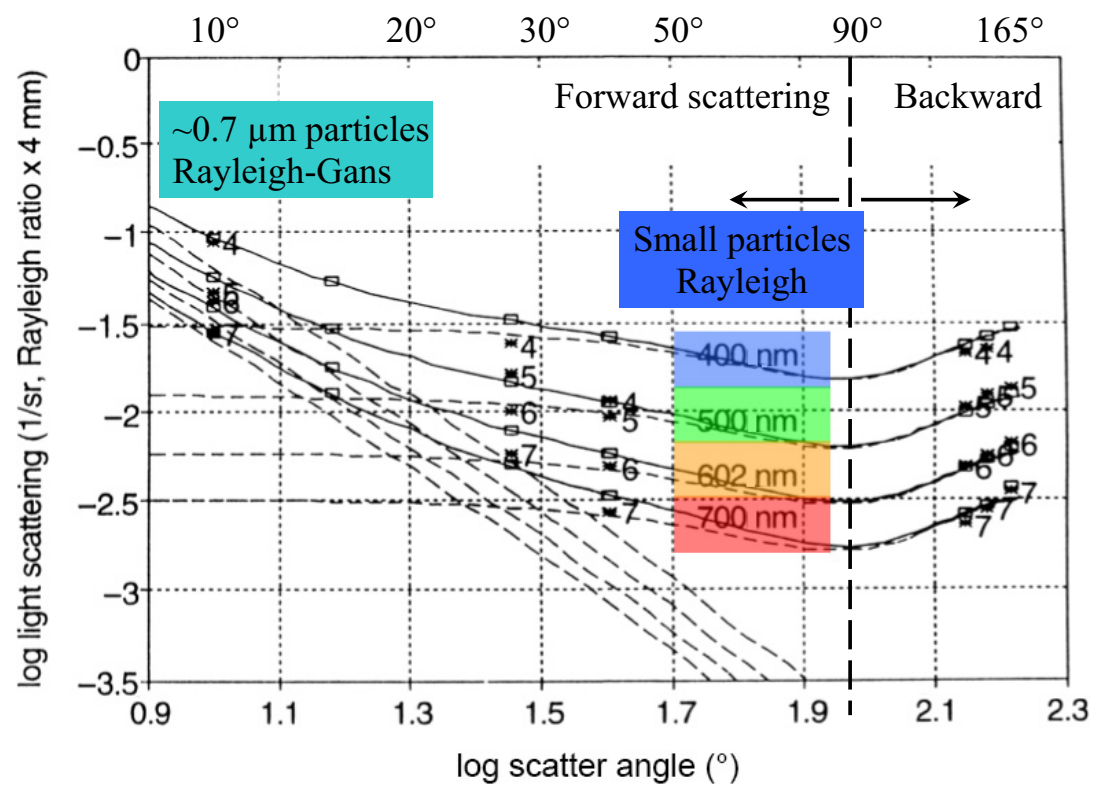

Figure 10. Angular dependence of light scattering at the center of the lens of a 50-year-old donor for four wavelengths indicated as $4=400 \mathrm{~nm}$, $5=500 \mathrm{~nm}, 6=602 \mathrm{~nm}, 7=700 \mathrm{~nm}$. The experimental data are explained with a two component model: (1) the Rayleigh component (set of four dashed lines, widely apart, showing a minimum at $90^{\circ}$ because of the natural light correction). The Rayleigh component dominates from $40^{\circ}$ upward, including backward (towards the slit lamp) scatter. (2) the non-Rayleigh component (set of four sloping dashed lines) dominating in forward direction as important for vision. The four dashed lines of this component are less widely apart because the wavelength dependence of this component is less strong. Figure modified from an earlier publication. ${ }^{21}$

for these lenses, the reduction of the general light level would be of the order of $5 \%$. Since $80 \%$ of the light forms the proper image, and the general retinal light level corresponds to $95 \%$ of the light, it follows that overall the contrast in the retinal image would change by a factor of 0.80 / $0.95=0.84$, or $0.07 \log$ units. This effect on contrast would not be of great visual importance, nor would the loss of absolute light level. This discussion underlines that the functional effect of stray light depends on the presence of local luminances causing a veil of light over the darker areas.

Let us consider the densest lens of Figure 13 though (Lens 2). This lens shows extinction values of 0.43 and 0.34 for the Rayleigh and non-Rayleigh component 


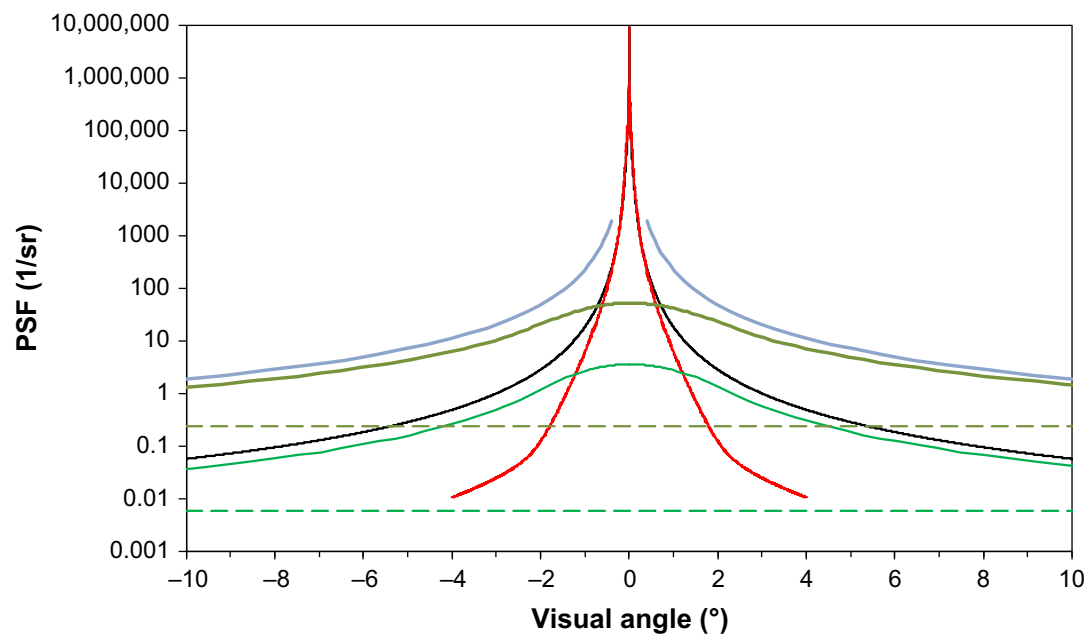

Figure 11. Model PSF of the human eye for a normal case and a case with increased light scatter (black and grey respectively), compared to the two major optical phenomena, total aberration (red), and lens light scatter (green). The scatter is broken down in the Rayleigh component (dashed) and in the non-Rayleigh component (continuous). The PSF models are according the CIE standard for the effects of scatter (glare) on the PSF, mainly based on psychophysics. ${ }^{35}$ The green lines are from in vitro measurements on donor eye lenses. The red line is based on the aberration model of Thibos et al. for normal eyes. ${ }^{37,38}$ The black and light green lines are for the young normal condition, the grey and dark green lines are for a cataractous condition. The scatter $\left(>1^{\circ}\right)$ part of the PSF contains also contributions from the cornea, and other parts of the eye, making it a bit higher.

respectively. So, the densest lens can be estimated to reduce the direct light significantly (by about $77 \%$ ) on the basis of light scattering. The total amount of light entering the eye changes by only $22 \%$ because most of the light scattering is in the forward direction. As is the case for the other lenses, this would visually not be an important effect. The contrast reduction in the retinal image would be important though, and can be estimated to be about $0.23 / 0.78=0.29$, or $0.53 \log$ units for this example. As mentioned above however, the straylight level of this lens is seldom encountered in the Western world. ${ }^{40}$ If we apply this calculation to another extreme (Lens 3, with forward extinction 0.21 and Rayleigh extinction 0.03 ) we arrive at a contrast loss of $0.75 / 0.98=0.77$ or $0.11 \log$ units. This discussion underlines that for a proper appreciation of the functional effect of light scattering, we must not consider solely the intensity of the scattered light. Instead, we must consider the ratio between that intensity and the amount of light in the direct beam. As it happens, often this is automatically guaranteed by the experimental setting. In vitro, as well as in vivo (psychophysical straylight), the scattered light is measured by comparison to direct light. Relevance for this has been discussed. ${ }^{43}$

\section{Local variations in the eye lens}

Lens layering

Upon slit lamp observation of the human eye lens, clear local variation can be seen, such as to distinguish the nucleus from the cortex, and a many-layered structure throughout the lens. ${ }^{44}$ Indeed, the back scattering data also show differences as function of location, as do the forward scattering data. Figure 14 gives an example for $140^{\circ}$ scatter angle, comparing the centre of the lens (horizontally), with the anterior part at $20 \%$ depth (vertically). Differences around $0.1 \log$ unit $(25 \%)$ in intensity of back scatter show up in this figure. This may seem little, but such difference is easily seen by the human observer. Although scatter intensities may differ over lens depth, the Rayleigh nature of back scatter was found to be present all over the lens, as was the non-Rayleigh nature of forward scatter (not illustrated).

\section{Zones of discontinuity or Wasserspalten}

More important differences as a function of depth are found if we look at more closely backward directions. Figure 15 shows results for the same depths as Figure 14, that $i s$, at the centre (horizontally), vs $20 \%$ depth (vertically), but for the $165^{\circ}$ scatter angle. At $20 \%$ depth, backward scatter is clearly more intense, but quite variably so. If we look at this behaviour in detail, we find that it corresponds with the so called zones of discontinuity. ${ }^{44,45}$ These zones are also clearly seen in the first row of the Lens Opacity Classification System (LOCS) chart reproduced in Figure 6. It was found that the additional backscatter at this angle (in addition to the Rayleigh scatter), is spectrally neutral, and rises sharply for more close backward angles. This corresponds to the general belief that those zones are discontinuities between layers of lens fibres and watery layers, hence 


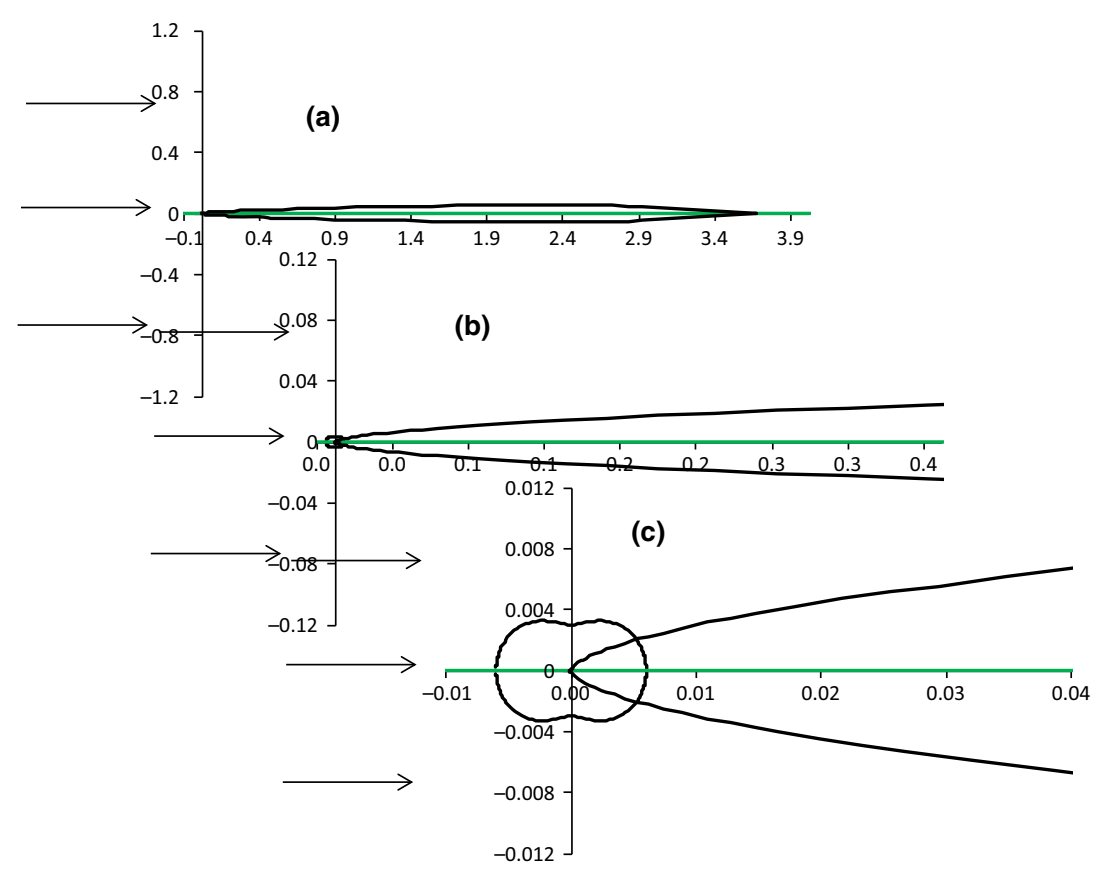

Figure 12. (a) Scatter diagram for a human eye lens, broken down in the non-Rayleigh, and the Rayleigh (too small to be seen) component. The numbers along both axis give the fraction of the incident light scattered per steradian. For example, at the right-most point in (c), the light scattered is given by a vector from the origin to that point over $\arctan (0.007 / 0.04)=10^{\circ}$ with the value $\left.\sqrt{\left(0.007^{2}\right.}+0.04^{2}\right)=0.0406$ per steradian (compare Figure 11). The half width is about $\pm 1.5^{\circ}$, which corresponds to 0.002 steradian. The central peak of direct light (not drawn) would extend as a narrow line a milion times to the right (see Figure 11). (b and c) give magnifications by $10 \times$ and $100 \times$ respectively, to show the relationship with the light scattered over larger angles. Because the amount of steradians involved is much larger at larger angles, still a considerable fraction is scattered there. Only in (c) can the Rayleigh component be clearly seen.

the name Wasserspalten in German, ${ }^{44}$ waterclefts in English. If those layers would be parallel to the surface of the lens, they would give the same kind of reflection as seen with the Purkinje images. They seem to be more irregular surfaces though. In some applications the wording rough surface reflection is used for a comparable phenomenon. In slit lamp observation it is well know that the Wasserspalten show up stronger if one approaches the reflection angles, that is if the angles of illumination and observation are symmetrical with respect to the normal to the surface. ${ }^{44}$ Figure 16 is the same as Figure 10, but now for 20\% depth instead of the centre of the lens. The coloured line segments indicate the deviation from Rayleigh caused by this back scatter component. The deviations from Rayleigh at the steep backward directions seem to be strongest for $700 \mathrm{~nm}$, but it must be realized that this is relative because of the logarithmic scale. Because Rayleigh is weakest at $700 \mathrm{~nm}$, this spectrally neutral component shows up strongest at that wavelength. In absolute values the $700 \mathrm{~nm}$ addition is equal to those at the other wavelengths.

The fraction of light reflected at a jump in index of refraction from $n 1$ to $n 2$ strongly depends on the $n 1-n 2$ difference according to $R=[(n 1-n 2) /(n 1+n 2)]^{2}$ for beam incidence normal to the surface. Let us use the values at the surfaces of the lens: $n 1=1.3376$ to $n 2=1.38$ and $v . v .{ }^{46}$ and reflectivity is about $R=0.00024$. This seems an extremely low value, also if compared to the diffuse reflectivity from Rayleigh scattering. If we take as example $10 \%$ Rayleigh scatter, then reflectivity would be $5 \%$. In a normal viewing situation (Figure 1) a 5\% reflecting surface would be perceived as dark as coal. The angular distribution of the reflected light is very important for the intensity seen. Figure 16 shows that at $165^{\circ}$ both reflections are of about the same value. This can be understood because the light reflected from the Wasserspalten is concentrated in a narrow cone. If we assume a cone with radius $15^{\circ}$, its solid angle would be 0.22 steradian, and the light concentrated by a factor 30 compared to the spreading over $2 \pi$ steradian for diffuse light.

\section{Cortical and posterior subcapsular (PS) cataract and posterior capsular opacification (PCO)}

Rows two and three of the LOCS chart (Figure 6) show the appearance of cortical and PS cataracts in retro-illumination images. These images show the cataracts as grey areas against the orange glow of the fundus, which may suggest that these cataracts reduce the amount of light. It might be 


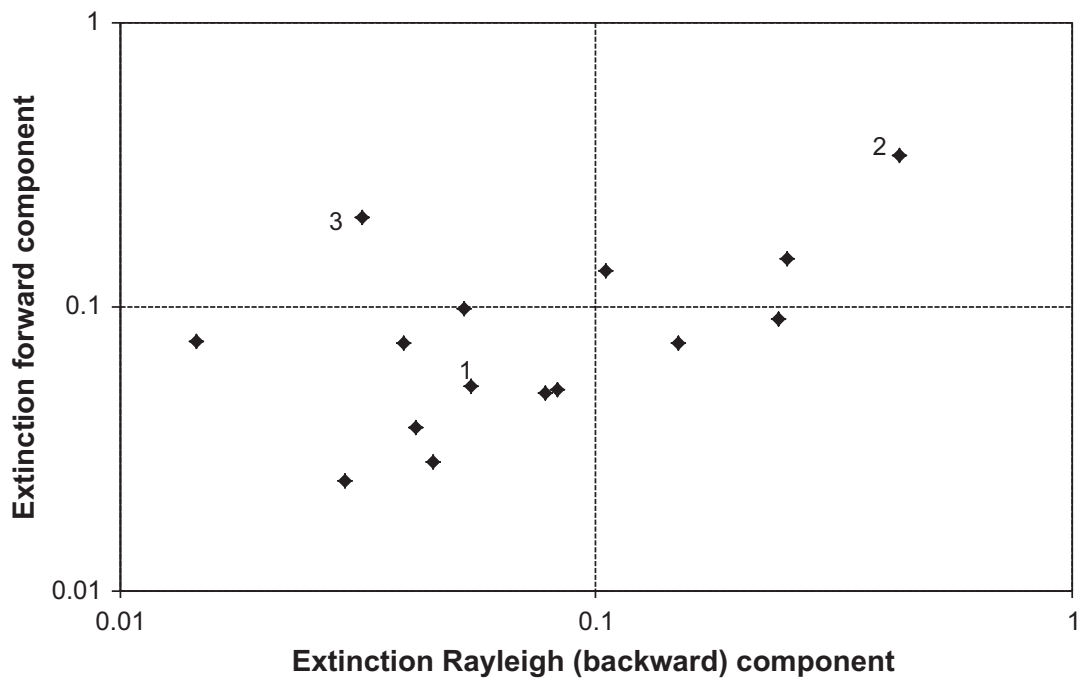

Figure 13. Extinction values defined according the norm in basic physical light scattering theory. Extinction is the fraction of light lost from the (ideal) direct beam. Exctinctions are given for both classes of particles identified in 15 human donor lenses. Horizontally, values are given for the Rayleigh particles, dominating in backward directions. Vertically, values are given for the particles dominating in forward directions $<40^{\circ}$.

thought that they contain absorptive pigments. The same may be the case for PCO. However, studies on all these types of cataracts showed strong straylight effects. $^{23,39,41,47,48}$ Moreover, an in vitro study on PCO showed corresponding light scattering effects, ${ }^{49}$ and another study showed that the light scattering effects explained the perceived reduction of the light. ${ }^{50}$ This is illustrated in Figure 17 from the same paper. The light scattering by PCO is more complicated though than described above for the crystalline lens, as it includes both a forward scatter component, and a refractive component, deflecting the light to smaller angles, as might be expected. ${ }^{49,50}$

A comparable study for cortical or PS cataract has not been performed. However, the darkening seen in the respective retro-illumination images is also not thought to be due to light absorption. If we realise that the acceptance angle of the camera or microscope used to observe the retro-illumination image in the clinic is of limited size (about $2^{\circ}$ to $5^{\circ}$ in radius), we can appreciate the perceived light reduction effect. The amount of light scattered over angles larger than $2^{\circ}$ to $5^{\circ}$ is lost to the clinician, and so, an area that scatters light relatively strongly will appear darker. The counterpart of this argument is that, if a camera with a larger acceptance angle would be used, the cataracts would show less pronounced in retro-illumination.

To evaluate this argument quantitatively we need to speculate somewhat because of the rather localised nature of these cataracts. The above studies found straylight elevations up to a factor of about 10. Pre-surgery straylight values were on average $\log (s)=1.55$ in a recent YAG laser capsulotomy study, ${ }^{51}$ as well as in a recent cataract surgery study, ${ }^{40}$ compared to $\log (\mathrm{s})=0.9$ in the young normal eye. ${ }^{30}$ The value of 1.55 corresponds to an equivalent age of 89 years according the above given formula. If we analyse the scatter diagram of the lens best fitting to this value of 1.55 (Lens 3 in Figure 13) we find that $18 \%$ (for $5^{\circ}$ ) or $13 \%$ (for $10^{\circ}$ ) is lost by scattering. However, we need to consider that in these cataracts only part of the pupil opening is usually covered by the cataract. If we assume that half of the pupil surface is covered, then we must multiply these values by two. These considerations suggest that scattering is an important factor in the seeming light weakening effect seen in the retro-illumination images of these cataracts. Since the scattering is mainly in forward directions, also these cataracts have little effect on the overall light level at the retina. One might also consider reflective effects from refractive index jumps surrounding cataractous areas. However, the discussion at the end of the section on Wasserspalten suggests that such reflectivity effects are unimportant to reduce light intensity.

\section{Aberrations and surfaces}

As stressed above, the present paper does not discuss aberrations. Aberrations as they are typically assessed clinically derive from a physically rather different phenomenon. They depend on refractive index variations over large scale compared to light scattering. Sampling scale in aberrometry typically is $0.2 \mathrm{~mm}$, whereas forward scattering derives from micrometre scale particles. Aberrations have effect over much smaller visual angles, and affect the central peak of the PSF only (Figure 11).

Light scatter must not be confused with aberrations. Light penetrating the eye is divided into two parts: a relatively 


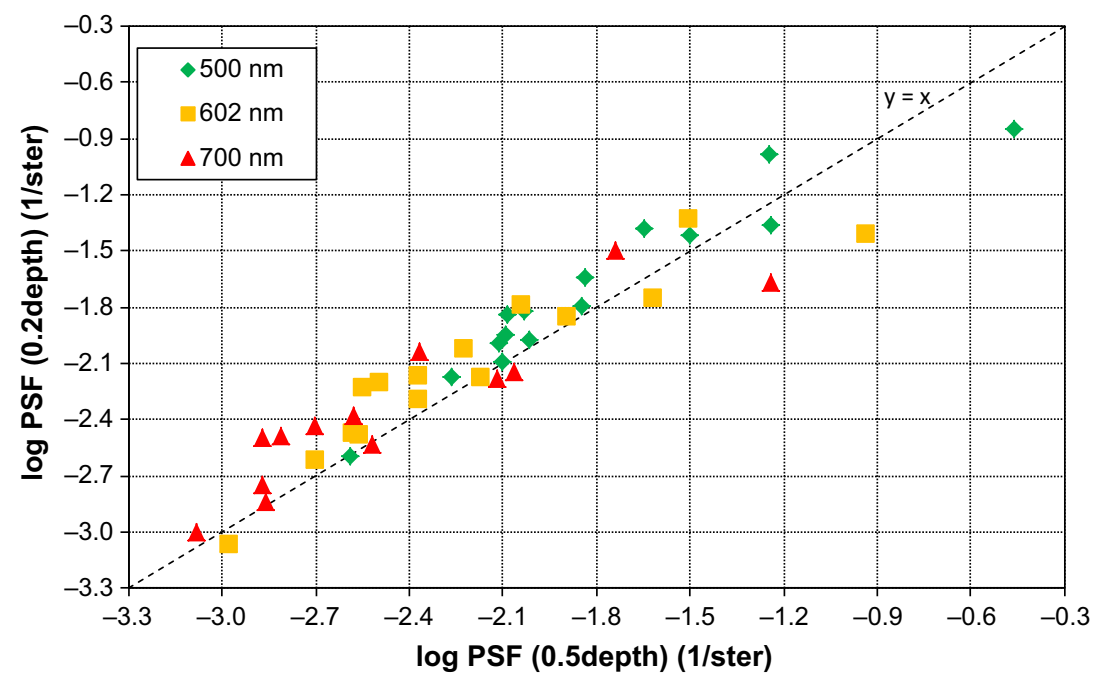

Figure 14. Comparison of light scattering over $140^{\circ}$ (backward scattering) for two locations in the lens. Horizontally results are given for the middle of the lens, and vertically for $20 \%$ depth (anterior part of the lens). At this angle Rayleigh scattering dominates. Differences between locations are limited. The same holds for other locations (not shown). The same also holds for all angles $<140^{\circ}$. One lens shows a difference of more than a factor 2 in this figure, in favor of the nucleus (points to the right in the figure).

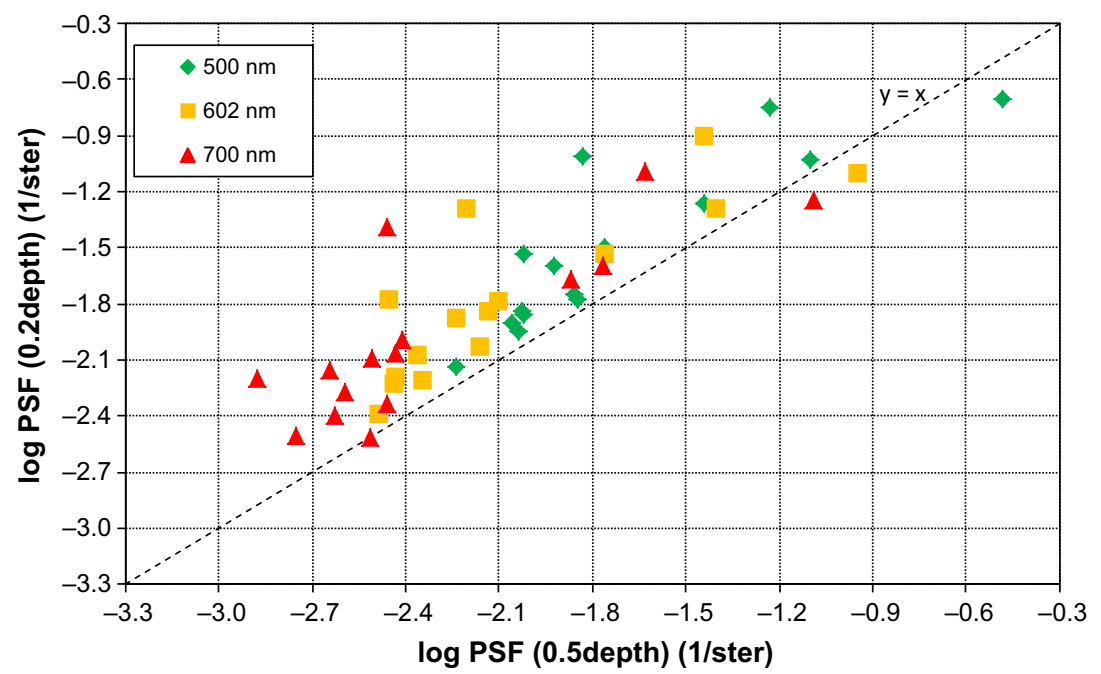

Figure 15. Same as Figure 14 , but for $165^{\circ}$ scatter angle (backward, closest to the reflection angle of $180^{\circ}$ ). Horizontally, results are given for the middle of the lens, and vertically for $20 \%$ depth (anterior part of the lens). Much stronger differences are seen in favor of the anterior location in the lens. The same holds for the location at $80 \%$ depth (posterior; not shown). At these locations the phenomenon of zones of discontinuity, or Waserspalten, occurs, which has been described to be reflective in nature. ${ }^{44}$ The angular dependence as well as the wavelength dependence of the light scatter measurements confirm this (rough surface reflection).

small part is scattered, and removed from the direct beam. Most of the light is not scattered, but continues as the direct beam. This non-scattered part is the basis for functional imaging, but its quality is under the control of aberrations. Aberrations deflect light mainly over small angles $\left(<1^{\circ}\right)$, whereas light scatter is important because of the straylight effects over large angles $\left(>1^{\circ}\right)$, causing problems like glare and hazy vision. Aberrations can be counteracted by adaptive optics, whereas scattering cannot. For an interesting early study on adaptive optics the reader is referred to Miller et al. ${ }^{52}$ and for the start of recent developments in this field to Williams, Liang and Roorda et al. . $^{53,54}$

One may wonder what effect the Wasserspalten have in forward directions. Since their light scattering spreads in backward directions over more than $10^{\circ}$, it may be thought that they also cause considerable light spreading in forward directions. However, in backward directions the scatter angles are dictated by the process of reflection. In that case, 


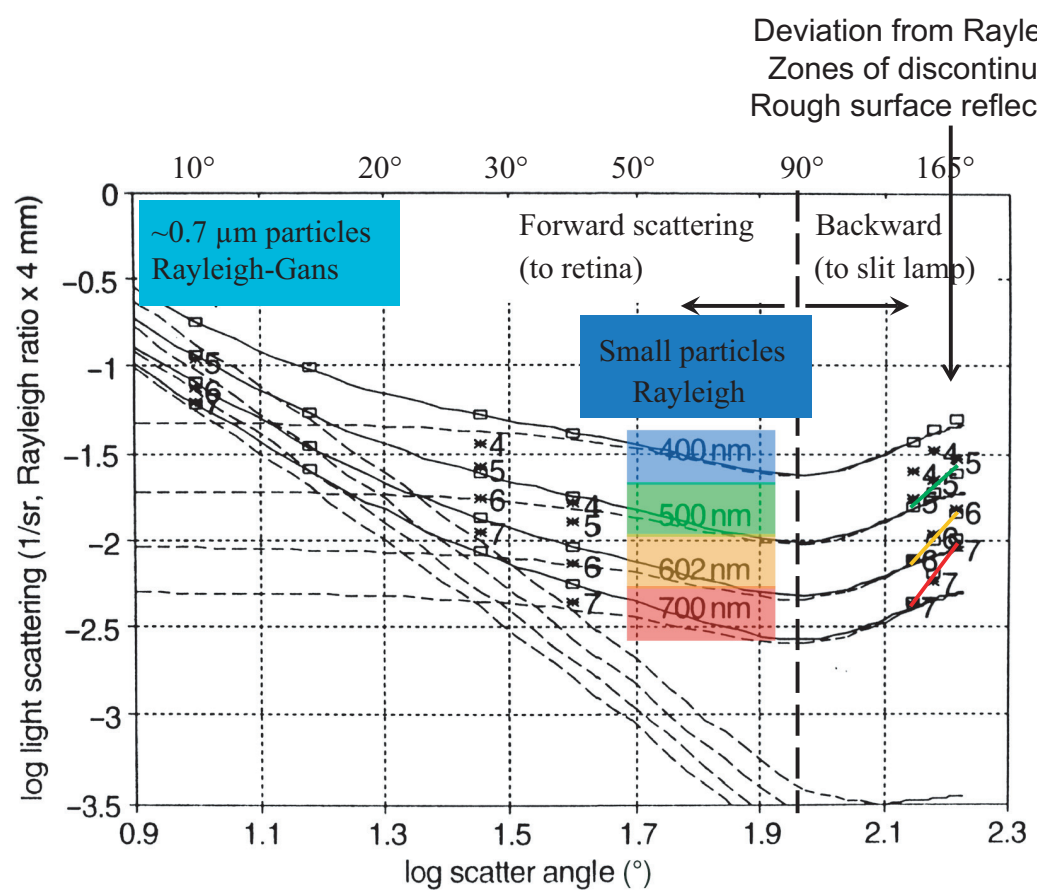

Figure 16. Same as Figure 10, but for a different location: Angular dependence of light scattering at $20 \%$ depth (anterior), and explained with three (not two) components: (1) the Rayleigh component (four dashed lines, widely apart), dominating from $40^{\circ}$ upward, including backward (towards the slit lamp) scatter, (2) the non-Rayleigh component (four sloping dashed lines) dominating for vision, and (3) rough surface reflection dominating for the most backward angles only (four coloured line segments). Figure modified from an earlier publication. ${ }^{21}$

scatter angle twice the full angular difference between incident ray and reflecting surface $\left(-180^{\circ}\right)$ applies. In forward directions on the other hand, Snell's law applies leading to a change of angle of $5 \%$ or less of the difference in angle between refracting surface and incident beam $\left(-90^{\circ}\right)$. So, in forward directions the deflection angle is more than $40 \times$ less as compared to backward directions and is very small, so that it falls in the central peak of the PSF, governed by aberrations.

Another example is the (rough) anterior surface of the lens. Its orange peel surface causes the third Purkinje image to be quite blurred, but its consequence for the retinal image is small because of an estimated difference in index of refraction of 1.3376 to $1.38 .{ }^{46}$ Using these figures, one arrives at $3 \%$ change of angle.

At the front of the cornea, the eye has one more such rough surface, the front of the epithelium. This surface can become functionally very important if the tear film is lacking, because of a much larger jump in index of refraction. The associated aberrations are different from those normally considered and have been elegantly coined micro-aberrations by Thibos et al. ${ }^{55}$ The effect of a dry eye on the central peak of the PSF can be quite strong. ${ }^{55}$ Of course the normal aberrations, with their larger spatial scales, dominate the PSF peak in most cases, including cataracts. ${ }^{56-58}$
One might wonder whether a correlation exists between aberrations and the light scattering in case of cataracts or other conditions of the eye. A recent paper in the present journal reviewed this question and concluded that the two phenomena are quite independent. ${ }^{36}$ Large population studies have shown little statistical correlation to exist between visual acuity and straylight in cataracts and corneal conditions. $^{24,40,59-64}$ Theoretical and methodological underpinning was given. ${ }^{36}$

\section{Absorption and fluorescence}

\section{Absorption}

The optical section slit lamp image of the human eye lens shows the increased absorption of the lens with age and nuclear cataract (see the first row of Figure 6). It must be realised though that the intensity of colouration seen in the slit lamp is much stronger compared to that experienced by the eye itself. As mentioned above, the difference is more than a factor 2 in density. One can appreciate the difference by looking at the colour at less than half the lens depth in Figure 6. The eye experiences that kind of colouration, not the colouration seen at the posterior side of the slit lamp image. The cornea seems to lack absorption in the visual range of wavelengths; it only scatters light. ${ }^{42,65}$ Thorough studies have illuminated the spectral characteristics of lens 


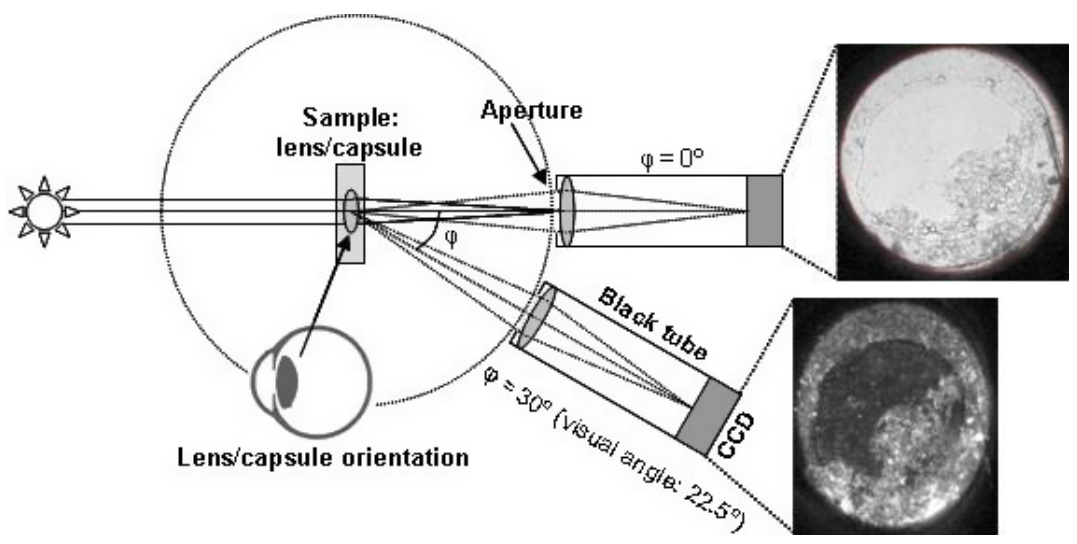

Figure 17. In vitro imaging of PCO. The upper image uses direct illumination. A retro-illumination image would look more or less the same. The PCO shows up as grey area, which might suggest the PCO reduces the light by absorption. However, when we look at another angle (lower image), PCO shows up as lighter. This indicates that PCO scatters light. The scattered light is lost from the direct illumination image, hence the darkening in that image. Close scrutiny of the two images reveals a correlation between dark areas/points in the upper, and light areas/points in the lower figure. Picture reproduced from a study by van Bree et al. ${ }^{50}$ with permission.

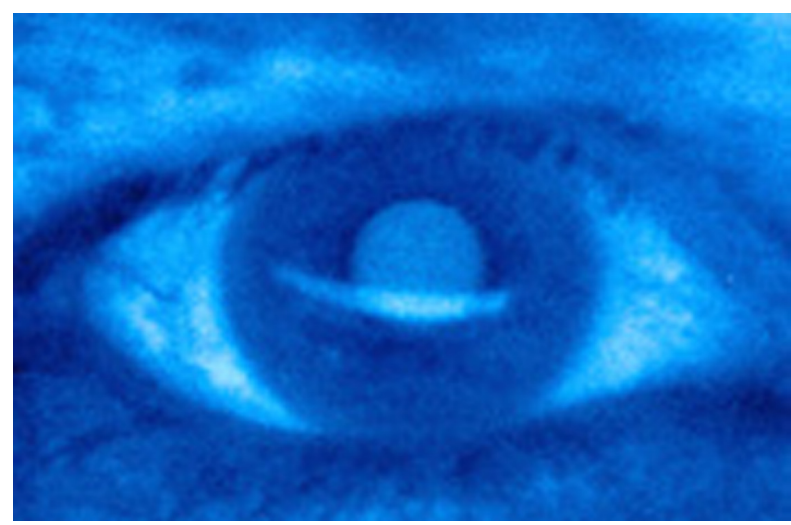

Figure 18. Fluorescence of the eye lens (and other parts of the eye and face), when illuminated with a black light. A black light emits virtually invisible UV light, and is typically known as a party light. In general, protein containing substances show fluorescence. The arc at the bottom of the pupil is the (first) Purkinje reflex of the tube light source.

absorption. ${ }^{13,42,66}$ Using the very precise methods of colorimetry, Pokorny and Smith developed a much used two component model for lens absorption. ${ }^{66}$ One component is stable throughout life, being non-zero below $450 \mathrm{~nm}$ only, with a density of 1.0 at $400 \mathrm{~nm}$. The other component does increase with age. At 20, 65, and 80 years of age the model gives at the peak of the visual spectrum densities of 0.06 ,

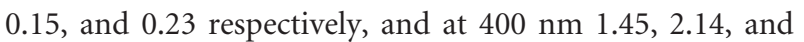
2.74 respectively. One may conclude that the effect on overall luminosity is limited, but that the effect on colour can be significant. The pigments responsible have been identified. Tryptophan, which is rather independent from age, and two pigments increasing with age, resulting from protein degradation. ${ }^{67-71}$

\section{Fluorescence}

Those three pigments also have fluorescent effects, with excitation maxima at 290,370 , and $430 \mathrm{~nm}$ respectively, and emission maxima at 332, 440, and $500 \mathrm{~nm}$ respectively. ${ }^{69}$ Many authors have realised that fluorescence may have visual significance. ${ }^{72-76}$ The fluorophores transform short wavelength light of low visual efficiency, to longer wavelength light of much higher visual efficiency. This is called inelastic light scattering, as opposed to elastic light scattering, when no wavelength change and the associated loss of photon energy occurs. However, fluorescent emission is isotropic. The directionality of the light is completely lost. As a result, the fluorescent light is not experienced as coming from the (short wavelength) source, but fills the visual field in a nondescript way. The effect can be experienced when one is exposed to a so-called 'black' light, popular at parties. The lens fluorescence can be compared to scattered light but with angular dependence more similar to that of Rayleigh scattering and in particular the circular component shown in Figure 2. So, although the light is transformed to more efficient light, it is not useful, and acts as a veiling luminance to reduce the contrast of the image. As for general straylight, the disturbance is conditional and depends on the ratio between the intensities of the straylight source and the visual task. ${ }^{75}$

With an adaptation to the in vitro set-up of Figure 3, lens fluorescence was also measured to assess potential visual effectiveness. ${ }^{77}$ For excitation wavelengths 380,400 and $420 \mathrm{~nm}$, the emission spectrum was determined and compared to spectra from the literature. ${ }^{74}$ Quantum efficiency proved to vary from $0.05(5 \%)$ for a 69 -year-old lens at $380 \mathrm{~nm}$ excitation, to $0.004(0.4 \%)$ for a 22 -year-old lens at 
$420 \mathrm{~nm}$ excitation. Visual efficiency was calculated using the spectral sensitivity curves for the human eye and retina. As expected, luminous efficiency ratio was much higher. It was a factor of $0.22-0.71$ for $420 \mathrm{~nm}, 2.7-6.8$ for $400 \mathrm{~nm}$, and $71-151$ for $380 \mathrm{~nm}{ }^{77,78}$ From this result it may seem that fluorescence is visually unimportant from $420 \mathrm{~nm}$ upward. However, a more proper appreciation of the visual relevance must include a comparison to the PSF. ${ }^{78}$ The relevant question would be at what angle does the isotropic background from fluorescence surpass the peripheral part of the normal PSF? With normal, the above mentioned PSF is meant, including elastic light scattering only. As an example, if one compares the basic CIE PSF (see the black line in Figure 10) to isotropic lights with $100 \times, 10 \times$, and $1 \times$ its total luminous value, the two would cross at $0.92^{\circ}$, $2.2^{\circ}$, and $6.4^{\circ}$ respectively. ${ }^{78}$ From such a comparison it follows that the fluorescence generated by $380 \mathrm{~nm}$ light surpasses its PSF at about $1^{\circ}$. For $420 \mathrm{~nm}$ the crossing point is at about $10^{\circ}$. So, even for $420 \mathrm{~nm}$ part of the PSF/straylight is dominated by fluorescence. Hence, we can understand that fluorescence can have a significant impact on glare hindrance. ${ }^{75}$ For broad band glare lights, fluorescence is less important. For example, for equal energy light or daylight conditions one can estimate on the basis of the figures above that fluorescence may contribute less than $1 \%$ luminosity. So, it may be important for very large angles only.

\section{Other media errors}

A multitude of other media disturbances exist that can be better understood using knowledge about light scattering. It is not possible to discuss them all, but a few relevant subjects follow.

\section{Fundus reflectance and eye wall transmittance}

Part of the straylight experienced by the young normal eye originates from diffuse reflection from the fundus, ${ }^{22}$ and from diffuse transmittance of the eye wall. ${ }^{79}$ Both are strongly dependent on the degree of pigmentation of the eye. ${ }^{79-81}$ In case pigmentation is defective, as in albinos or other conditions, straylight elevation can be a serious problem to vision. ${ }^{82,83}$

\section{Cornea}

Also the cornea contributes significantly to the straylight level in young subjects. ${ }^{22}$ With ageing, for normal eyes its contribution remains relatively constant as compared to the contribution of the eye lens. ${ }^{65}$ The cornea seems extremely sensitive to straylight elevation depending on condition. To name but a few effects, many studies have shown increased straylight with contact lenses, ${ }^{30,84-87}$ contact lens induced oedema, ${ }^{88,89}$ and Fuch's dystrophy. ${ }^{90-92}$ As with the crystalline lens, the intensity of back scatter as observed with the slit lamp is not very predictive of forward scatter. ${ }^{93}$ McCally and Farrell published a series of thorough studies on light scattering by the cornea, including theoretical predictions. ${ }^{8}$ Meek and Knupp recently published an excellent review. $^{10}$

\section{Dot-like or localised opacities}

Several conditions exist that can be described as dot-like opacities, such as crystalline corneal dystrophy (Schnyders dystrophy), retrodots and vacuoles in the crystalline lens, Cerulean cataract, Christmas tree cataract, pulverulent congenital cataract, glistenings in implant lenses, laser pits from YAG capsulotomy on implant lenses, Mittendorf's dot, asteroid hyalosis in the vitreous, etc. Such dots may appear very bright and disturbing to the clinician at the slit-lamp. It is often met with surprise that the patients are little bothered, and that visual acuity is well preserved. This can be understood if the (light scattering) effects are considered quantitatively, as discussed earlier (see Figure 9 in van den Berg, Coppens and Franssen). ${ }^{94,95}$ The important quantity to consider is the fraction of light intercepted by the dots. Although the dots can be very bright, their surface is often small, and the total surface occupied may cover only $1 \%$ of the pupil opening. Such coverage would lower retinal contrast of a letter chart by $1 \%$ maximally. In case the surface covered would be $10 \%$, the slit lamp image would seem terrible, but the scattering would have no effect whatsoever on measured acuity, and very little effect on contrast sensitivity. ${ }^{36,94,96}$ The straylight effect can be extremely bothersome though. ${ }^{24,60}$

\section{Pseudophakia and implant lenses}

Cataract extraction and lens implantation have been found to be effective in reducing straylight. ${ }^{40,97-99}$ This also occurs for so called clear lens extraction for refractive surgery, but now this can be understood because the (normally aged) eye lens scatters significantly. ${ }^{100}$ However, the postoperative straylight level does on average not return to the level of the young eye, even if PCO is excluded. ${ }^{101}$ It is presently unclear what the precise reasons are for the straylight level in uncompromised pseudophakia. Partly the implant lenses are to blame as it was found by many researchers that implant lenses can scatter light for a variety of reasons, often without much acuity effects, in particular deposits and interocular lens material degradation such as glistenings. ${ }^{102-108}$ Often the problem shows up clearly in the slit lamp image, but not always. ${ }^{109}$ 


\section{Acknowledgements}

Sources of inspiration for this review are gratefully acknowledged: Dave Elliott for suggesting this review and listing a formidable set of questions; Ivanka van der Meulen and Nic Reus for many discussions on the nature of cataracts and other media disturbances. Joris Coppens and Luuk Franssen have been important in different aspects of my studies, as have many others.

\section{Disclosure}

The Royal Netherlands Academy of Arts and Sciences owns a patent on stray light measurement (van den Berg, inventor) and licenses this to Oculus for the C-Quant instrument.

\section{References}

1. Maurice DM. The structure and transparency of the cornea. J Physiol 1957; 136: 263-286.

2. Trokel S. The physical basis for transparency of the crystalline lens. Invest Ophthalmol 1962; 1: 493-501.

3. Benedek GB. Theory of transparency of the eye. Appl Opt 1971; 10: 459-473.

4. Bell MM, Ross DS, Bautista MP et al. Statistical-thermodynamic model for light scattering from eye lens protein mixtures. J Chem Phys 2017; 146: 055101.

5. Bettelheim FA \& Kumbar M. An interpretation of smallangle light-scattering patterns of human cornea. Invest Ophthalmol Vis Sci 1977; 16: 233-236.

6. Bettelheim FA. Physical basis of lens transparency. In: The Ocular Lens: The Structure, Function, and Pathology (Maisel H, editor), Dekker: New York, NY, 1985; pp. 265-300.

7. Tardieu A \& Delaye M. Eye lens transparency analyzed by $\mathrm{x}$-ray and light scattering. The lens: Transparency and cataract. (Duncan G, editor) Eurage 1986; pp. 49-57.

8. McCally RL \& Farrell RA. Light Scattering From Cornea and Corneal Transparency, Springer: New York, NY, 1990.

9. Meek KM \& Quantock AJ. The use of X-ray scattering techniques to determine corneal ultrastructure. Prog Retin Eye Res 2001; 20: 95-137.

10. Meek KM \& Knupp C. Corneal structure and transparency. Prog Retin Eye Res 2015; 49: 1-16.

11. van den Berg TJTP. Depth-dependent forward light scattering by donor lenses. Invest Ophthalmol Vis Sci 1996; 37: 1157-1166.

12. Chylack LT Jr, Wolfe JK, Singer DM et al. The lens opacities classification system III. The Longitudinal Study of Cataract Study Group. Arch Ophthalmol 1993; 111: 831836.

13. Norren DV \& Vos JJ. Spectral transmission of the human ocular media. Vision Res 1974; 14: 1237-1244.
14. Tardieu A. Eye lens proteins and transparency: from light transmission theory to solution X-ray structural analysis. Annu Rev Biophys Biophys Chem 1988; 17: 47-70.

15. Allen MJ \& Vos JJ. Ocular scattered light and visual performance as a function of age. Am J Optom Arch Am Acad Optom 1967; 44: 717-727.

16. Weale RA. Real light scatter in the human crystalline lens. Graefes Arch Clin Exp Ophthalmol 1986; 224: 463 466.

17. McLaren JW, Bourne WM \& Patel SV. Standardization of corneal haze measurement in confocal microscopy. Invest Ophthalmol Vis Sci 2010; 51: 5610-5616.

18. van de Hulst HC. Light Scattering by Small Particles. Dover Publications Inc.: New York, NY, 1981.

19. Gilliland KO, Freel CD, Lane CW, Fowler WC \& Costello MJ. Multilamellar bodies as potential scattering particles in human age-related nuclear cataracts. Mol Vis 2001; 7: 120 130 .

20. Costello MJ, Johnsen S, Gilliland KO, Freel CD \& Fowler WC. Predicted light scattering from particles observed in human age-related nuclear cataracts using mie scattering theory. Invest Ophthalmol Vis Sci 2007; 48: 303-312.

21. van den Berg TJTP \& Spekreijse H. Light scattering model for donor lenses as a function of depth. Vision Res 1999; 39: 1437-1445.

22. Vos JJ. Disability glare - a state of the art report. Commission International de L'Eclairage J 1984; 3/2: 39-53.

23. Paulsson LE \& Sjöstrand J. Contrast sensitivity in the presence of a glare light. Theoretical concepts and preliminary clinical studies. Invest Ophthalmol Vis Sci 1980; 19: 401406.

24. van den Berg TJTP. Importance of pathological intraocular light scatter for visual disability. Doc Ophthalmol 1986; 61: 327-333.

25. Applegate RA, Trick LR, Meade DL \& Hartstein J. Radial keratotomy increases the effects of disability glare: initial results. Ann Ophthalmol 1987; 19: 293-297.

26. Barbur JL, de Cunha D, Harlow A \& Woodward EG. Methods for the measurement and analysis of light scattered in the human eye. Non-invasive Assessment of the Visual System. OSA Technical Digest Series; 1993; pp. 170-173.

27. Whitaker D, Elliott DB \& Steen R. Confirmation of the validity of the psychophysical light scattering factor. Invest Ophthalmol Vis Sci 1994; 35: 317-321.

28. Hennelly ML, Barbur JL, Edgar DF \& Woodward EG. The effect of age on the light scattering characteristics of the eye. Ophthalmic Physiol Opt 1998; 18: 197-203.

29. van den Berg TJTP, Franssen L \& Coppens JE. Straylight in the human eye: testing objectivity and optical character of the psychophysical measurement. Ophthalmic Physiol Opt 2009; 29: 345-350.

30. van den Berg TJTP, Franssen L, Kruijt B \& Coppens JE. History of ocular straylight measurement: a review. $Z$ Med Phys 2013; 23: 6-20. 
31. Ginis H, Perez GM, Bueno JM \& Artal P. The wide-angle point spread function of the human eye reconstructed by a new optical method. J Vis 2012; 12: 20.

32. van den Berg TJTP. To the editor: Intra- and intersession repeatability of a double-pass instrument. Optom Vis Sci 2010; 87: 920-921.

33. Pinero DP, Ortiz D \& Alio JL. Ocular scattering. Optom Vis Sci 2010; 87: E682-E696.

34. van den Berg TJTP \& Coppens JE, inventors. Method and device for measuring retinal straylight. WO2005023103, NL1024232C. 2005.

35. Vos JJ \& van den Berg TJTP. Report on disability glare. CIE Collection 1999; 135: 1-9.

36. van den Berg TJTP. The (lack of) relation between straylight and visual acuity. Two domains of the point-spreadfunction. Ophthalmic Physiol Opt 2017; 37: 333-341.

37. Thibos LN, Bradley A \& Hong X. A statistical model of the aberration structure of normal, well-corrected eyes. Ophthalmic Physiol Opt 2002; 22: 427-433.

38. Thibos LN, Hong X, Bradley A \& Cheng X. Statistical variation of aberration structure and image quality in a normal population of healthy eyes. J Opt Soc Am A Opt Image Sci Vis 2002; 19: 2329-2348.

39. Elliott DB, Gilchrist J \& Whitaker D. Contrast sensitivity and glare sensitivity changes with three types of cataract morphology: are these techniques necessary in a clinical evaluation of cataract? Ophthalmic Physiol Opt 1989; 9: 25-30.

40. van der Meulen IJE, Gjertsen J, Kruijt B et al. Straylight measurements as an indication for cataract surgery. J Cataract Refract Surg 2012; 38: 840-848.

41. de Waard PW, IJspeert JK, van den Berg TJTP \& de Jong PT. Intraocular light scattering in age-related cataracts. Invest Ophthalmol Vis Sci 1992; 33: 618-625.

42. Boettner EA \& Wolter JR. Transmission of the ocular media. Invest Ophthalmol 1962; 1: 776-783.

43. van den Berg TJTP. Analysis of intraocular straylight, especially in relation to age. Optom Vis Sci 1995; 72: 52-59.

44. Goldmann H. Senile changes of the lens and the vitreous. Am J Ophthalmol 1964; 57: 1-13.

45. Bahrami M, Hoshino M, Pierscionek B, Yagi N, Regini J \& Uesugi K. Optical properties of the lens: an explanation for the zones of discontinuity. Exp Eye Res 2014; 124: 93-99.

46. Navarro R, Mendez-Morales JA \& Santamaria J. Optical quality of the eye lens surfaces from roughness and diffusion measurements. J Opt Soc Am A 1986; 3: 228234.

47. Abrahamsson M \& Sjöstrand J. Impairment of contrast sensitivity function (CSF) as a measure of disability glare. Invest Ophthalmol Vis Sci 1986; 27: 1131-1136.

48. van Bree MC, van den Berg TJ \& Zijlmans BL. Posterior capsule opacification severity, assessed with straylight measurement, as main indicator of early visual function deterioration. Ophthalmology 2013; 120: 20-33.
49. van Bree MC, van der Meulen IJ, Franssen L, Coppens JE, Zijlmans BL \& van den Berg TJ. In-vitro recording of forward light-scatter by human lens capsules and different types of posterior capsule opacification. Exp Eye Res 2012; 96: 138-146.

50. van Bree MC, van der Meulen IJ, Franssen L et al. Imaging of forward light-scatter by opacified posterior capsules isolated from pseudophakic donor eyes. Invest Ophthalmol Vis Sci 2011; 52: 5587-5597.

51. van Bree MCJ, Zijlmans BLM \& van den Berg TJTP. Effect of neodymium:YAG laser capsulotomy on retinal straylight values in patients with posterior capsule opacification. $J$ Cataract Refract Surg 2008; 34: 1681-1686.

52. Miller D, Zuckerman JL \& Reynolds GO. Holographic filter to negate the effect of cataract. Arch Ophthalmol 1973; 90: 323-326.

53. Liang J, Williams DR \& Miller DT. Supernormal vision and high-resolution retinal imaging through adaptive optics. $J$ Opt Soc Am A Opt Image Sci Vis 1997; 14: 2884-2892.

54. Roorda A. Adaptive optics for studying visual function: a comprehensive review. J Vis 2011; 11: 6.

55. Nam J, Thibos LN, Bradley A, Himebaugh N \& Liu H. Forward light scatter analysis of the eye in a spatially-resolved double-pass optical system. Opt Express 2011; 19: 7417-7438.

56. Sachdev N, Ormonde SE, Sherwin T \& McGhee CN. Higher-order aberrations of lenticular opacities. J Cataract Refract Surg 2004; 30: 1642-1648.

57. Rocha KM, Nose W, Bottos K, Bottos J, Morimoto L \& Soriano E. Higher-order aberrations of age-related cataract. J Cataract Refract Surg 2007; 33: 1442-1446.

58. Lee J, Kim MJ \& Tchah H. Higher-order aberrations induced by nuclear cataract. J Cataract Refract Surg 2008; 34: 2104-2109.

59. Elliott DB \& Bullimore MA. Assessing the reliability, discriminative ability, and validity of disability glare tests. Invest Ophthalmol Vis Sci 1993; 34: 108-119.

60. van den Berg TJTP, Hwan BS \& Delleman JW. The intraocular straylight function in some hereditary corneal dystrophies. Doc Ophthalmol 1993; 85: 13-19.

61. van den Berg TJTP, van Rijn LJ, Michael R et al. Straylight effects with aging and lens extraction. Am J Ophthalmol 2007; 144: 358-363.

62. Michael R, van Rijn LJ, van den Berg TJTP et al. Association of lens opacities, intraocular straylight, contrast sensitivity and visual acuity in European drivers. Acta Ophthalmol 2009; 87: 666-671.

63. Bal T, Coeckelbergh T, Van LJ, Rozema JJ \& Tassignon MJ. Influence of cataract morphology on straylight and contrast sensitivity and its relevance to fitness to drive. Ophthalmologica 2011; 225: 105-111.

64. McLaren JW \& Patel SV. Modeling the effect of forward scatter and aberrations on visual acuity after endothelial keratoplasty. Invest Ophthalmol Vis Sci 2012; 53: 55455551. 
65. van den Berg TJTP \& Tan KE. Light transmittance of the human cornea from 320 to $700 \mathrm{~nm}$ for different ages. Vision Res 1994; 34: 1453-1456.

66. Pokorny J, Smith VC \& Lutze M. Aging of the human lens. Appl Opt 1987; 26: 1437-1440.

67. Said FS \& Weale RA. The variation with age of the spectral transmissivity of the living human crystalline lens. Gerontologia 1959; 3: 213-231.

68. Cooper GF \& Robson JG. The yellow colour of the lens of man and other primates. J Physiol 1969; 203: 411-417.

69. Lerman S \& Borkman R. Ultraviolet radiation in the aging and cataractous lens. A survey. Acta Ophthalmol (Copenh) 1978; 56: 139-149.

70. Lerman S. Biophysical aspects of corneal and lenticular transparency. Curr Eye Res 1984; 3: 3-14.

71. Pierscionek BK \& Weale RA. The optics of the eye-lens and lenticular senescence. A review. Doc Ophthalmol 1995; 89: 321-335.

72. le Grand Y. Recherches sur la Fluorescence des Milieux Oculaires, Instituto de Biofisica, Universidade do Brasil: Rio de Janeiro, 1948.

73. Weale RA. Human lenticular fluorescence and transmissivity, and their effects on vision. Exp Eye Res 1985; 41: 457473.

74. Zuclich JA, Glickman RD \& Menendez AR. In situ measurements of lens fluorescence and its interference with visual function. Invest Ophthalmol Vis Sci 1992; 33: 410415.

75. Elliott DB, Yang KC, Dumbleton K \& Cullen AP. Ultraviolet-induced lenticular fluorescence: intraocular straylight affecting visual function. Vision Res 1993; 33: 1827-1833.

76. Pierscionek BK \& Weale RA. Lenticular scattered and fluorescent light: biomicroscopic determination of their relative proportions. Exp Eye Res 1997; 64: 189-194.

77. van den Berg TJ. Quantal and visual efficiency of fluorescence in the lens of the human eye. Invest Ophthalmol Vis Sci 1993; 34: 3566-3573.

78. van den Berg TJ. Visual efficiency of scattering and fluorescence in the human eye lens. J Biomed Opt 1996; 1: 262-267.

79. van den Berg TJTP, IJspeert JK \& de Waard PW. Dependence of intraocular straylight on pigmentation and light transmission through the ocular wall. Vision Res 1991; 31: 1361-1367.

80. Nischler C, Michael R, Wintersteller C et al. Iris color and visual functions. Graefes Arch Clin Exp Ophthalmol 2013; 251: 195-202.

81. Coppens JE, Franssen L \& van den Berg TJTP. Wavelength dependence of intraocular straylight. Exp Eye Res 2006; 82: 688-692.

82. La Hey E, IJspeert JK, van den Berg TJ \& Kijlstra A. Quantitative analysis of iris translucency in Fuchs' heterochromic cyclitis. Invest Ophthalmol Vis Sci 1993; 34: 2931-2942.

83. Kruijt B, Franssen L, Prick LJ, van Vliet JM \& van den Berg TJ. Ocular straylight in albinism. Optom Vis Sci 2011; 88: E585-E592.
84. Applegate RA \& Wolf M. Disability glare increased by hydrogel lens wear. Am J Optom Physiol Opt 1987; 64: 309312.

85. Applegate RA \& Jones DH. Disability glare and hydrogel lens wear-revisited. Optom Vis Sci 1989; 66: 756-759.

86. Cervino A, Gonzalez-Meijome JM, Linhares JM, Hosking SL \& Montes-Mico R. Effect of sport-tinted contact lenses for contrast enhancement on retinal straylight measurements. Ophthalmic Physiol Opt 2008; 28: 151-156.

87. Hofmann T, Zuberbuhler B, Cervino A, Montes-Mico R \& Haefliger E. Retinal straylight and complaint scores 18 months after implantation of the AcrySof monofocal and ReSTOR diffractive intraocular lenses. J Refract Surg 2009; 25: 485-492.

88. Elliott DB, Fonn D, Flanagan J \& Doughty M. Relative sensitivity of clinical tests to hydrophilic lens-induced corneal thickness changes. Optom Vis Sci 1993; 70: 1044-1048.

89. Fonn D, Du TR, Simpson TL, Vega JA, Situ P \& Chalmers RL. Sympathetic swelling response of the control eye to soft lenses in the other eye. Invest Ophthalmol Vis Sci 1999; 40: 3116-3121.

90. Ahmed KA, McLaren JW, Baratz KH, Maguire LJ, Kittleson KM \& Patel SV. Host and graft thickness after Descemet stripping endothelial keratoplasty for Fuchs endothelial dystrophy. Am J Ophthalmol 2010; 150: 490-497.

91. Cheng YY, van den Berg TJ, Schouten JS et al. Quality of vision after femtosecond laser-assisted descemet stripping endothelial keratoplasty and penetrating keratoplasty: a randomized, multicenter clinical trial. Am J Ophthalmol 2011; 152: 556-566.

92. van der Meulen IJ, Patel SV, Lapid-Gortzak R, Nieuwendaal CP, McLaren JW \& van den Berg TJ. Quality of vision in patients with fuchs endothelial dystrophy and after descemet stripping endothelial keratoplasty. Arch Ophthalmol 2011; 129: 1537-1542.

93. Patel SV, Baratz KH, Hodge DO, Maguire LJ \& McLaren JW. The effect of corneal light scatter on vision after descemet stripping with endothelial keratoplasty. Arch Ophthalmol 2009; 127: 153-160.

94. van den Berg TJTP, Coppens JE \& Franssen L. Ocular media clarity and straylight. In: Encyclopedia of the eye (Dart DA, editor), Academic Press: Oxford, 2010; pp. 173183.

95. Kruijt B \& van den Berg TJ. Optical scattering measurements of laser induced damage in the intraocular lens. PLoS One 2012; 7: e31764.

96. Labuz G, Reus NJ \& van den Berg TJ. Straylight from glistenings in intraocular lenses: In vitro study. J Cataract Refract Surg 2017; 43: 102-108.

97. Claesson M, Klaren L, Beckman C \& Sjöstrand J. Glare and contrast sensitivity before and after Nd:YAG laser capsulotomy. Acta Ophthalmol (Copenh) 1994; 72: 27-32.

98. Hard AL, Beckman C \& Sjöstrand J. Glare measurements before and after cataract surgery. Acta Ophthalmol (Copenh) 1993; 71: 471-476. 
99. Witmer FK, van den Brom HJ, Kooijman AC \& Blanksma LJ. Intra-ocular light scatter in pseudophakia. Doc Ophthalmol 1989; 72: 335-340.

100. Lapid-Gortzak R, van der Meulen IJ, van der Linden JW, Mourits MP \& van den Berg TJ. Straylight before and after phacoemulsification in eyes with preoperative corrected distance visual acuity better than $0.1 \operatorname{logMAR}$. J Cataract Refract Surg 2014; 40: 748-755.

101. Labuz G, Reus NJ \& van den Berg TJ. Ocular straylight in the normal pseudophakic eye. J Cataract Refract Surg 2015; 41: 1406-1415.

102. Werner L, Stover JC, Schwiegerling J \& Das KK. Light scattering, straylight, and optical quality in hydrophobic acrylic intraocular lenses with subsurface nanoglistenings. J Cataract Refract Surg 2016; 42: 148-156.

103. Werner L. Glistenings and surface light scattering in intraocular lenses. J Cataract Refract Surg 2010; 36: 13981420 .

104. Blundell MS, Mayer EJ, Knox Cartwright NE, Hunt LP, Tole DM \& Dick AD. The effect on visual function of
Hydroview intraocular lens opacification: a cross-sectional study. Eye (Lond) 2010; 24: 1590-1598.

105. Das KK, Stover JC, Schwiegerling J \& Karakelle M. Technique for measuring forward light scatter in intraocular lenses. J Cataract Refract Surg 2013; 39: 770-778.

106. van der Mooren M, Rosen R, Franssen L, Lundstrom L \& Piers P. Degradation of visual performance with increasing levels of retinal stray light. Invest Ophthalmol Vis Sci 2016; 57: 5443-5448.

107. Langeslag MJ, van der Mooren M, Beiko GH \& Piers PA. Impact of intraocular lens material and design on light scatter: In vitro study. J Cataract Refract Surg 2014; 40: 2120-2127.

108. van der Mooren M, Franssen L \& Piers P. Effects of glistenings in intraocular lenses. Biomed Opt Express 2013; 4: 1294-1304.

109. Labuz G, Papadatou E, Vargas-Martin F, Lopez-Gil N, Reus NJ \& van den Berg TJTP. Validation of a spectral light scattering method to differentiate large from small particles in intraocular lenses. Biomed Opt Express 2017; 8: 1889-1994.

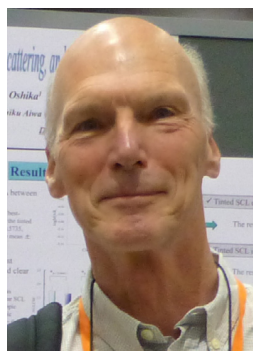

\section{Tom van den Berg}

Thomas J. T. P. van den Berg Ph.D. was born in Amsterdam in 1946. After graduating in Experimental Physics he worked in university education. His research focused on the visual system, later with an accent on clinical application. Since 1971 he has been with the University of Amsterdam as associateprofessor, gradually moving to pure research at institutes of the Netherlands Royal Academy. Since 1999 he headed the Physics department of the Institute for Neuroscience. He developed an instrument for assessment of ocular straylight, the cause for blinding during driving at night, now commercialized by Oculus as the "C-Quant". 